\title{
Limitations of Rock Mechanics in Energy-Resource Recovery and Development
}

\author{
Report of a \\ Study Conducted by the \\ Panel on Rock Mechanics Problems \\ That Limit Energy Resource \\ Recovery and Development
}

U.S. National Committee for Rock Mechanics Assembly of Mathematical and Physical Sciences National Research Council

NATIONAL ACADEMY OF SCIENCES

Washington, D.C. $\quad 1978$

$$
\begin{aligned}
& \text { This report was prepared as an account of work } \\
& \text { sponsored by the United States Government. Neither the } \\
& \text { United States nor the United States Department of } \\
& \text { Energy, nor any of their employees, nor any of their } \\
& \text { contractors, subcontractors, or their employees, makes } \\
& \text { any warranty, express or implied, or assumes any legal } \\
& \text { liability or responsibility for the accuracy, completeness } \\
& \text { or usefulness of any information, apparatus, product or } \\
& \text { process disclosed, of represents that its use would not } \\
& \text { infringe privately owned rights. }
\end{aligned}
$$




\section{DISCLAIMER}

This report was prepared as an account of work sponsored by an agency of the United States Government. Neither the United States Government nor any agency Thereof, nor any of their employees, makes any warranty, express or implied, or assumes any legal liability or responsibility for the accuracy, completeness, or usefulness of any information, apparatus, product, or process disclosed, or represents that its use would not infringe privately owned rights. Reference herein to any specific commercial product, process, or service by trade name, trademark, manufacturer, or otherwise does not necessarily constitute or imply its endorsement, recommendation, or favoring by the United States Government or any agency thereof. The views and opinions of authors expressed herein do not necessarily state or reflect those of the United States Government or any agency thereof. 


\section{DISCLAIMER}

Portions of this document may be illegible in electronic image products. Images are produced from the best available original document. 
NOTICE: The project that is the subject of this report was approved by the Governing Board of the National Research Council, whose members are drawn from the Councils of the National Academy of Sciences, the National Academy of Engineering, and the Institute of Medicine. The members of the Panel responsible for the report were chosen for their special competence and with regard for appropriate balance.

This report has been reviewed by a group other than the authors according to procedures approved by a report review committee consisting of members of the National Academy of Sciences, the National Academy of Engineering, and the Institute of Medicine.

SPONSORS: This project was supported by the following federal government agencies: Energy Research and Development Administration (Division of Oil, Gas, and Shale Technology; Division of Geothermal Energy; and Division of Reactor Research and Development), U.S. Bureau of Mines, U.S. Bureau of Reclamation, U.S. Geological Survey, Department of Transportation (Office of the Secretary), Federal Highway Administration, Urban Mass Transportation Administration, Defense Nuclear Agency, Department of the Air Force (Office of Scientific Research), Department of the Army (Corps of Engineers and Mobility, Equipment, Research and Development Command), Department of the Navy (Facilities Engineering Command), and National. Science Foundation.

Available from

National Technical Information Service

5285 Port Royal Road

Springfield, Virginia 22161

Report No. NRC/AMPS/RM-78-1

Price: North America - $\$ 6.00$ for paper copy and $\$ 3.00$ for microfiche Foreign - $\quad \$ 12.00$ for paper copy and $\$ 4.50$ for microfiche

A limited number of copies available for agencies and institutions on request to U.S. National Committee for Rock Mechanics

National Research Council

2101 Constitution Avenue, N.W.

Washington, D.C. 20418

Printed in the United States of America 


\section{FOREWORD}

The critical role of rock mechanics in meeting the U.S. energy demands was well established long before the Ad Hoc Panel on Rock Mechanics Problems That Limit Energy Resource Recovery and Development was convened and before the individual energy-resource areas were reviewed by the Subpanels. All our fossil energy-oil, gas, and coal-comes from the ground, as does our geothermal energy. Our nuclear-energy resource requires extensive uranium exploration and mining efforts, and to provide environmentally safe facilities, substantial efforts to site nuclear plants in suitable rocks and soils must be made. The safe disposal of the radioactive waste material is also being limited to some extent by rock-mechanics problems. Our hydroelectric energy resources require analysis of both rocks and soils for dams and foundations. National strategic crude-oil storage and storage of other fuels or energy sources are being paced by our engineering ability to construct economically and environmentally acceptable underground rock facilities.

In addition to the demands to meet energy needs is the need for environmentally acceptable methods. Rock mechanics plays a key role in achieving the compromises that will be made-for example, strip mining of coal as opposed to underground mining or geothermal-energy extraction with acceptable subsidence rather than unacceptable subsidence.

The experts who composed the Panel on Rock Mechanics Problems That Limit Energy Resource Recovery and Development have concluded that rock-mechanics problems critically limit energy-resource recovery and development. In some areas breakthroughs are required. In some situations the rock mechanics problems pose technical restraints that cannot be overcome at any cost, and in others they pose only serious financial constraints. Little research that would lead to these breakthroughs was found to be under way.

Within industry, rock mechanics is sometimes regarded as the micromechanics of rock deformation or possibly somewhat more broadly as the mechanics of rock behavior. The fact remains that rock mechanics, even in its application, is a means to the end not the end product. For this reason, this step in the solution of problems will not receive the direct attention that 
would be given to the end product. Rock-mechanics research to advance the state of the art is difficult for industry to justify because the time required to recover research investments is so long. The efforts that are being made by industry are spotty and are most likely to be site- and problem-specific. Rock-mechanics programs are expanded and contracted with current, specific problems for the company involved.

For U.S. Government-funded programs, mission agencies view rock mechanics in a manner similar to that of industry. The immediacy of specific problem solution would generally tend to preclude a deliberate attempt to advance the state of the art. Federally supported rock-mechanics programs would probably be site-specific, just as they are for industry. The National Science Foundation engineering and excavation programs, and very limited budgets within some mission agencies, are devoted primarily to rock mechanics research; even these programs tend to fluctuate with the requirements of more immediate national needs.

Because rock mechanics is not an end product but a means of moving toward the final solution of a problem, applying the necessary resources to achieve breakthroughs requires a concentrated effort by both industry and government. Many members of the Panel considered that the lack of a coordinated and constant effort in the field of rock-mechanics research could seriously hamper future energy-resource recovery in the United States. The Panel suggests that this research be given high priority by industry and government.

Sidney J. Green, Chairman

Panel on Rock Mechanics Problems That

Limit Energy Resource Recovery and Development 


\section{PREFACE}

The Ad Hoc Panel on Rock Mechanics Problems That Limit Energy Resource Recovery and Development was created within the U.S. National Committee for Rock Mechanics of the National Research Council. Its purpose was to define limitations imposed by rock-mechanics problems on energy-resource recovery and development and to recommend promising research that will help to remove those limitations. The Committee, in formulating the Panel's role, arranged for communication with supporting government agencies and developed a plan for selected Subpanels.

A briefing was given in June 1976, primarily to government agencies, to present the planned activities of the Panel. A Steering Group was formed, which selected nominees for the Subpanels. These nominations were submitted to the National Research Council for appointment of members. Six Subpane1s were established to deal with specific energy resource and development areas:

- Geothermal Energy Exploration and Production

- Mining and In Situ Recovery

- Nuclear-Waste Disposal

- $0 i 1$ and Gas Recovery

- Underground Storage-Fuel Oil, Gas, Water, or Compressed Air

- Under-Ocean Tunneling for Petroleum Recovery

The first five Subpanels deal with energy resources that are of current, immediate interest and application. The sixth Subpanel represents a response to advance a high-potential energy-recovery method. Because no other forum has openly addressed this recovery method, the opportumity and need existed for this Subpanel to study this method broadly.

The Panel Chairman presented the Subpanel Chairmen and members with the following guidelines:

- Take a broad view of the subject.

- Address the near-term-five years and less-problems in detail and the intermediate and long-range problems to the extent possible. 
- View rock mechanics as geotechnical or geomechanics, not in any sense a limited micromechanics interest.

- Characterize each energy resource from exploration to utilization.

- Define the limitations.

- Detail the nature and extent of the limitation.

- Recommend broad research, development, demonstration, test, or evaluations to help remove the limitations.

The members selected represented experts in a wide range of disciplines, ranging from rock micromechanics to management and program planning. The diverse talent and interests offered an excellent opportunity for exchange of information among the participants, who represented industry, universities, and government; hence the exchange of information covered an unusually broad area of interest.

Each of the Subpanels established an overview of its particular energy resource, defined the rock-mechanics-related limitations, and made practical recommendations to help to remove these limitations. This information is included in the individual Subpanel reports.

The complete Panel met in Washington, D.C., on January 13-15, 1977. The individual Subpanels subsequently submitted their reports, and a Summary and Conclusions were later developed to complete the report.

It should be noted that neither nuclear-power-plant siting nor seismic risks in general were included in the Panel effort because another National Research Council committee has been formed to address these areas. This Panel report will, however, provide backup information on specific rock-mechanics problems to this committee. 


\title{
PANEL ON ROCK MECHANICS PROBLEMS
}

\section{THAT LIMIT ENERGY RESOURCE RECOVERY AND DEVELOPMENT*}

\author{
Sidney J. Green, Chairman \\ President \\ Terra Tek \\ Salt Lake City, Utah \\ Ellis L. Armstrong \\ Consultant \\ Salt Lake City, Utah \\ John W. Handin \\ Director \\ Center for Tectonophysics \\ Texas A\&M University \\ Wi1liam C. McClain \\ Nuclear Division \\ Union Carbide Corporation \\ Oak Ridge, Tennessee
}

George B. Wallace

Principal Engineer

Bovay Engineers

Spokane, Washington

Liaison Representatives

Thomas C. Atchison

Chairman-Elect, USNC/RM

and Chairman, Panel on Domestic and International Activities

* See Appendix for membership of U.S. National Committee for Rock Mechanics 
William A. Hustrulid

Chairman, USNC/RM Panel on Fundamental Problems in Rock Mechanics and Educational Requirements

Ronald E. Heuer

Chairman, USNC/RM Panel on Rock Mechanics Problems Related to Underground Construction and Tunneling

SUBPANEL ON GEOTHERMAL ENERGY EXPLORATION AND PRODUCTION

T. William Thompson, Chairman

Department of Petroleum Engineering

University of Texas, Austin

Donald W. Brown

Group Q-11

Los Alamos Scientific Laboratory

Los Alamos, New Mexico

Sheldon E. Elliott

Branch Manager

Phillips Petroleum

Bartlesville, Oklahoma

Gregory L. Nesbitt

Manager, Fuel Resources

San Diego Gas and Electric

San Diego, California

Observer

Clifton B. McFarland

Program Manager, Utilization Technology

Division of Geothermal Energy

Energy Research and Development Administration*

Washington, D.C.

SUBPANEL ON MINING AND IN SITU RECOVERY

Hilmar A. Von Schonfeldt, Chairman

Occidental Research Corporation

La Verne, California

Wilson Blake

Consultant

Hayden Lake, Idaho

* Now part of the Department of Energy 
Carl G. Broadbent

Metal Mining Division

Kennecott Copper Corporation

Salt Lake City, Utah

James N. Johnson

Group T-4

Los Alamos Scientific Laboratory

Los Alamos, New Mexico

William G. Pariseau

Department of Mineral Engineering

University of Utah

David T. Snow

Department of Geology

Colorado School of Mines

Observers

Robert Hard

Director

Ledgemont Laboratory

Lexington, Massachusetts

Joe Pasini

Energy Research and Development Administration*

Morgantown, West Virginia

SUBPANEL ON NUCLEAR-WASTE DISPOSAL

Wolfgang R. Wawersik, Chairman

Geomechanics Research Division

Sandia Laboratories

Albuquerque, New Mexico

Bruce R. C1ark

Department of Geology and Mineralogy

University of Michigan

John W. Handin

Director

Center for Tectonophysics

Texas AGM University

M. Ashraf Mahtab

Senior Rock Mechanics Engineer

Acres Consulting Services, Ltd.

Niagara Falls, Ontario, Canada

*Now part of the Department of Energy 
James E. Russell

Nuclear Division

Union Carbide Corporation

Oak Ridge, Tennessee

Paul A. Witherspoon, Jr.

Lawrence Berkeley Laboratory

University of California, Berkeley

\section{Observers}

William Bishop

Nuclear Regulatory Commission

Washington, D.C.

George Debuchananne

U.S. Geological Survey

Reston, Virginia

Owen Gormley

Energy Research and Development Administration*

Washington, D.C.

Robert Leachman

Nuclear Regulatory Commission

Washington, D.C.

SUBPANEL ON OIL AND GAS RECOVERY

Henry J. Ramey, Chairman

Department of Petroleum Engineering

Stanford University

Rodney J. C1ifton

Division of Engineering

Brown University

Robert M. Forrest

Manager, Supply Research

Columbia Gas Systems Service Corporation

Columbus, Ohio

Kate H. Hadley

Senior Research Geologist

Exxon Production Research Company

Houston, Texas

Henry B. Woods

Consultant

Houston, Texas

*Now part of the Department of Energy 
Observer

Alex Crawley

Division of Fossil Energy

Energy Research and Development Administration*

Washington, D.C.

SUBPANEL ON UNDERGROUND STORAGE - FUEL OIL, GAS, WATER, OR COMPRESSED AIR

Dougal R. McCreath, Chairman

Head, Geotechnical Department

Acres American, Inc.

Buffalo, New York

E1lis L. Armstrong

Consultant

Salt Lake City, Utah

Richard E. Goodman

Department of Civil Engineering

University of California, Berkeley

Norman L. Hawes

Manager, Special Projects

Southern California Gas Company

Los Angeles, California

Charles H. Jacoby

Manager, Mining and Mineral Engineering

International Salt Company

Clarks Summit, Pennsylvania

John G. Lewis

Division Manager, Energy and Energy Related Projects

$R$ \& $D$ Associates

Marina Del Ray, California

Jeffrey H. Rumbaugh

Senior Staff Engineer, System Engineering and Operations

Potomac Electric Power Company

Washington, D.C.

Observers

Robert Davies

Federal Energy Administration*

Washington, D.C.

* Now part of the Department of Energy 
William W. Hakala

Program Manager, Excavation Technology

Advanced Productivity Research and Technology Division

National Science Foundation

Washington, D.C.

Philip. Lowe

Office of Internal Review

Energy Research and Development Administration*

Washington, D.C.

J. Charles Smith

Division of Electrical Energy Systems

Energy Research and Development Administration*

Washington, D.C.

De Marquis D. Wyatt

Committee on Advanced Energy Storage Systems

Assembly of Engineering

National Research Council

Washington, D.C.

SUBPANEL ON UNDER-OCEAN TUNNELING FOR PETROLEUM RECOVERY

H. Donald Outmans, Chairman

Research Associate

Union Oil-Union Research Center

Brea, California

J. Donovan Jacobs

Chairman

Jacobs Associates

San Francisco, California

Hans 0. Jahns

Exxon Production Research Company

Houston, Texas

William C. Maurer

President

Maurer Engineering, Inc.

Houston, Texas

Terence G. McCusker

Manager, Tunne1 Division

Perini Corporation

Fort Lee, New Jersey

*Now part of the Department of Energy 
Ma1colm Mellor

Experimental Engineering Division

U.S. Army Cold Regions Research and Engineering Laboratory

Hanover, New Hampshire

William M. Sackinger

Geophysical Institute

University of Alaska, College/Fairbanks

Observer

Harold F. Yde

Getty Oil

Houston, Texas

\section{STAFF}

U.S. National Committee for Rock Mechanics

0. Allen Israelsen, Executive Secretary

Susan V. Heisler, Assistant Executive Secretary

Barbara S. Adams, Administrative Assistant

Carole B. Carstater, Secretary 
$\theta$

$\theta$ 


\section{CONTENTS}

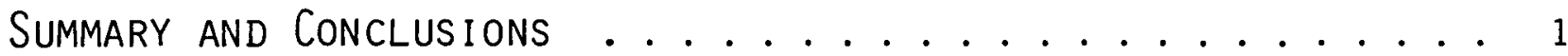
Reports of the Subpanels

1 GEOTHERMAL ENERGY EXPLORATION AND PRODUCTION . . . . . . . . . . . 7

2 MINING AND IN SITU RECOVERY . . . . . . . . . . . . . 21

3 NUCLEAR-WASTE DISPOSAL . . . . . . . . . . . . . 27

4 OIL AND GAS RECOVERY . . . . . . . . . . . . . . . 35

5 UNDERGROUND STORAGE - FUEL OIL, GAS, WATER, OR COMPRESSED AIR . . . . . 43

6 UNDER-OCEAN TUNNELING FOR PETROLEUM RECOVERY . . . . . . . 53 APPENDIX

MEMBERSHIP 1976-1977,

U.S. NATIONAL COMMITTEE FOR ROCK MECHANICS . . . . . . . . . 65 


\section{SUMMARY AND CONCLUSIONS}

\section{SIGNIFICANCE OF ROCK-MECHANICS PROBLEM LIMITATIONS}

Many rock-mechanics problems are of great importance in the nation's striving for energy independence and critically limit energy-resource recovery and development. These problems cause limitations that adversely affect our capabilities to locate, evaluate, recover, and store energy resources. For example, our inability to predict porosity and permeability of rock masses, in situ in their natural states or modified by processes such as hydrofracturing, has adverse effects on many energy recovery and storage activities. Investigators have estimated ${ }^{l}$ that brown shales of the Eastern Devonian-Mississippian basins, tight sands of the Uninta, Green River, San Juan, and other Western basins, geopressured tight sands of the Gulf Coast, and Eastern and Western coals contain an amount of methane gas 200 or more times the amount of natural gas produced in the United States during 1975. Efforts are urgently needed to develop effective means for producing gas from these sources, which are at present underdeveloped.

Similarly, our inability to predict porosity and permeability of rock masses and to map fracture patterns and faults hampers the evaluation of geothermal reservoirs and the design of systems. for recovering and utilizing geothermal energy. Current estimates of the nation's total geothermal resource base $^{2}$ in natural steam, hot water, hot dry rock, and geopressured and normalgradient reservoirs indicate a potentially accessible source of energy several times greater than our total oil and gas resources. The rock-mechanics technological problems in evaluating the geothermal reservoirs and in improving their permeability require urgent attention.

\footnotetext{
${ }^{1}$ Board on Mineral Resources, NRC Commission on Natural Resources, 1976. Natural Gas from Unconventional Geologic Sources. National Academy of Sciences, Washington, D.C.

${ }^{2}$ D.E. White and D.L. Williams (Editors), 1975. Assessment of.Geothermal Resources of the United States-1975. U.S. Geologica1 Survey Circular 726, Washington, D.C.
} 
Prediction of porosity and permeability and mapping fractures of rock masses in situ are also key factors in nuclear-fuel utilization and in energy storage underground. Finding suitable depositories for very-1ong-term containment of radioactive wastes is dependent on accurate evaluation of migration of fluids through rock and development of methods to monitor fluid flows in environments in which the effects of high temperatures, stress states, fracture patterns, and chemical changes are unknown.

In situ recovery of energy from coal and oil shale is dependent on establishing relatively homogeneous porosity and permeability in producing zones. Without this technical development in rock mechanics, in situ energy recovery from coal and oil shale will not be possible, either technically or economically.

Also, much more must be understood about techniques for fragmenting rock in both drilling and excavating systems. Substantial savings of time, energy, and overall drilling and excavation costs probably can be achieved through a more complete understanding of rock-fragmentation processes. More information is needed concerning the influence of in situ stresses, pore-fluid pressure, jointing and joint orientation, and physical properties (including thermophysical and thermomechanical) of the rock materials on the effectiveness of the drilling or excavation system.

The method of recovering oil and gas offshore (particularly in the Arctic) by tunnels and chambers will not be utilized until the uncertainties of tunneling advance rates, of underground opening stability, and of underground oil-well drilling and production safety are significantly reduced. These are only some samples of existing rock-mechanics problems that were examined and that the Subpanel reports discuss in detail.

\section{SÚBPANEL CONCLUSIONS}

The six Subpanels (Geothermal Energy Exploration and Production, Mining and In Situ Recovery, Nuclear-Waste Disposal, Oil and Gas Recovery, Underground Storage, and Under-Ocean Tunneling) deliberated independently and made overal 1 assessments of limitations related to rock mechanics in each of the resource areas. The Subpanels concluded that rock-mechanics problems critically limit energy-resource recovery and development in many areas. The most serious of these limitations cited by the Subpanels are as follows:

\section{Geothermal Energy Exploration and Production}

- Problems in identifying, characterizing, and evaluating potential geothermal energy sites-barpiers to economic development of these resources. Needed are further developments of down-hole active and passive logging techniques, further development of surface geophysical techniques, determination of temperature effects on physical properties of reservoir rocks, and development of both equipment and interpretation techniques for site evaluations.

- Understanding of the mechanies of artificial fracturing. Improved techniques are needed for determining the reservoir-site in situ stress field; predicting results of thermal fracturing, and mapping fracture zones.

- Understanding compaction and thermal mechanies. More development is needed on theories of rock behavior at elevated temperatures, at high stresses, and at high pore-fluid pressures, of fluid flow in fractured rock systems, and of models for fractured rock response。 
- Characterization of recharge capacity in wet geothermal areas. Techniques are needed for identifying recharge areas and for investigation of recharge mechanisms.

- Evaluation of environmental impacts. Much more understanding is needed of the effects of in situ stresses, fluid pressures, and temperatures on seismic activation and subsidence mechanisms.

Mining and In Situ Recovery

- Problems of permeabizity control and roof control for in situ energy recovery from coal, oil shale, and tar sands. Needed are techniques to evaluate effects of elevated temperatures on sedimentary rock, effects of high loading rates in the explosive range, effects of stress and temperatures on permeability, and behavior of the residue.

- Remote sensing and modeling capabilities. Further development of radar, seismic, and other geophysical remote-sensing techniques and improved modeling techniques are needed to increase the efficiency and profitability of commercial-scale operations.

- Drilling and remote-control equipment. Significant improvements in equipment can be expected in the next 5 to 10 years if rock mechanics is applied toward improving the effectiveness of such equipment.

Nuclear-Waste Disposal

- Prediction over long time periods of the movement of fluids in rock. More understanding is needed for the thermomechanical, time-dependent properties of rock masses.

- Identification and description of fracture zones, fracture networks, and conomalous inclusions. Fracture mapping techniques are needed.

- Characterization of waste-disposal sites. More development is needed of methods and equipment for measuring rock-mass properties, in situ stress states, thermal loads, and groundwater regimes.

- Validation of design conalyses and procedures. Problems of scale, interpretation of laboratory test results, constitutive-relation model development, and thermomechanical analysis urgently need attention.

- Site monitoring capabilities. Strategies and instrumentation must be developed for monitoring in situ changes over long periods of time in adverse envi ronments.

\section{$0 i 1$ and Gas Recovery}

- Reservoir storage and delivery characterization. Basic studies are needed on porosity, permeability, and ductility variation with depth. Rugged high-temperature, high-pressure logging devices are required for down-hole measurements. Also, less expensive coring techniques and core analysis methods need to be developed.

- Improved drizling capability. Better tools, more thorough understanding of the fracture mechanics of fluid-filled rocks, and means of alleviating high hydrostatic pressures at the bottom of the drill hole are needed.

- More effective reservoir recovery. Improved techniques for in situ stress determination well away from a borehole would significantly advance reservoir exploitation by hydraulic fracturing.

- Safe Arctic drizing. More needs to be known of the mechanical properties of ice and permafrost. 
Underground Storage-Fuel 011 , Gas, Water, or Compressed Air

- Site characterization. Improved down-the-hole tools are required for better evaluation of in situ stress at depth and of characteristics at a distance from the exploration borehole.

- Containment evaluation and assurance. Predictive tools are needed to assess hydrogeology as are improved grouting materials applicable in a wide range of temperature conditions and better analytical understanding of waterinjection curtains for containment.

- Seismic response. Analytical and test data should be developed to assure integrity of underground storage facilities under earthquake conditions.

- Stability of solution-mined chambers in salt. Studies are needed of salt properties and variation of these properties with temperature.

Under-0cean Tunneling for Petroleum Recovery

- Behavior of permafrost. Experiments are needed to define cutting rates, creep, subsidence, heave, and similar effects when tunneling in permafrost and through its interface with unfrozen rock.

- Heat control. Studies are necessary to determine how heat can be managed during both tunneling and long-term facility operations in permafrost and ice.

- Muck removal. Potential problems associated with refreezing of permafrost cuttings and rubble must be solved.

- Safety. Existing hardware must be modified and systems adapted for safe operations for both personnel and equipment. Alternative escape systems also need to be developed.

\section{PRIORITY RESEARCH NEEDS}

In determining the limitations imposed by rock-mechanics problems in each of the energy-resource areas, the independent Subpanel deliberations produced common rock-mechanics research needs. It is particularly significant to note that the research needs for the individual areas overlap considerably. The methodology, the techniques, even the researchers needed to advance the state of the art are common to the various energy-resource areas. The breadth of the research necessary, however, is great. Physics, mechanics, engineering, geology, and geophysics must all be combined to remove the limitations imposed by rock-mechanics problems on energy-resource recovery and development.

Broad overall research needs are summarized here, with emphasis on common research of primary importance in the different energy-resource areas:

flow in situ

- Research to develop better methods for determining and obtaining shallow and deep in situ stresses

- Research to improve the ability to map fracture patterns, particularly major fractures and faults, at depth

- Research to improve the understanding of rock-fragmentation processes for increasing the effectiveness of drilling and excavation systems

- Research to increase understanding of the relation of laboratorymeasured quantities to in situ conditions

- Research to provide the thermophysical and thermomechanical properties of rock, including fractured rock 
In terms of total U.S. research and development expenditures, relatively little is being spent on rock-mechanics research in the United States. Because rock mechanics is not an end product, and the time required to recover research investments is so long, industry, with its limited resources, will concentrate on more immediate problem solving. Government mission agencies are under many of the same problem-solving constraints as industry. A concentrated effort is needed to provide and maintain research support eventually to achieve the needed improvements in energy-resource recovery and development.

The Panel emphasizes that it was organized and directed to define rockmechanics related limitations in energy-resource recovery and development and to recommend broad research to overcome these limitations. The Panel took only the initial steps that are required to develop the detailed research programs to conduct the high-priority research outlined above. A more detailed analysis of research under way and future opportunities in each of the above research areas, providing cost estimates, time schedules, milestones, laboratory and field programs, demonstrations, and verification efforts would considerably assist program managers and researchers. Another effort by a panel of somewhat different composition would be desirable to develop this information. 
0

0 
1

\section{GEOTHERMAL ENERGY EXPLORATION AND PRODUCTION}

T. William Thompson

Subpanel Chairman

\section{INTRODUCTION}

The exploitation of geothermal energy involves tapping the heat energy stored in the earth's crust. Hot rocks can always be found at some depth, but dril1ing and production costs and complexity limit the economic development of this energy source to areas where high temperatures are found near the surface. Localized upward displacement of isotherms can occur in areas of high-conductivity rocks, where near-surface rocks form an insulating blanket or where upward migration of molten rock, or hot waters, heats the upper strata. Many classical geothermal areas occur in areas of known volcanic or tectonic activity, where surface manifestations have led to the discovery of geothermal reservoirs.

In any geothermal area the mode of exploitation is dictated by the nature of the resource but always involves the removal of heat to the surface, where it may be used directly or converted to other forms of energy. Two major types of geothermal resource can be identified: resources where the rocks contain hot fluids in sufficient quantities to act as the heattransfer medium (Figure 1.1), and those where the hot rock is essentially dry (Figure 1.2). The first type includes hot water (hydrotherma1) and steam reservoirs. There is a gradation between these two kinds of reservoir and the type may change during fluid production, as pressure and temperature changes lead to phase changes of the reservoir fluid. By contrast the second type includes those resources where fluid is either absent or present in quantities too small to allow direct extraction of heat energy. This is the class of resource, commonly referred to as "hot dry" rock, from which heat must be extracted by injecting fluids. A third type of resource, allied closely to the first, is geopressured geothermal reservoirs in which the high-temperature fluid is at elevated pressure. These are less common, but are found in the sediments around the Gulf of Mexico, where they form a potentially important source of energy.

From the standpoint of rock mechanics, geothermal reservoirs may be divided into nonporous, which will always be hot-dry reservoirs, and porous, the latter class being further divided into reservoirs where the porosity is 


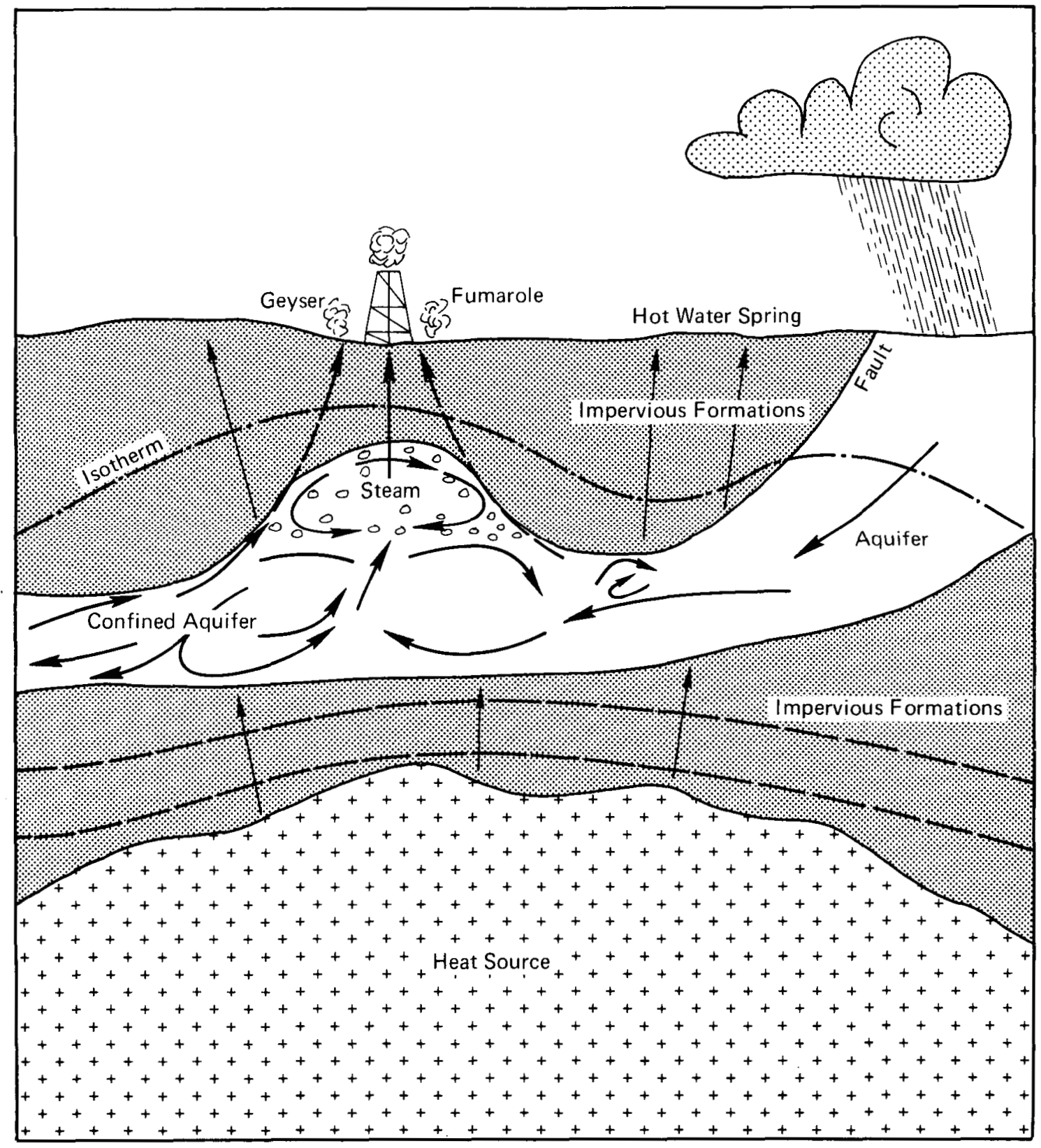

FIGURE 1.1 Schematic illustration of a steam-dominated hydrothermal geothermal system. 


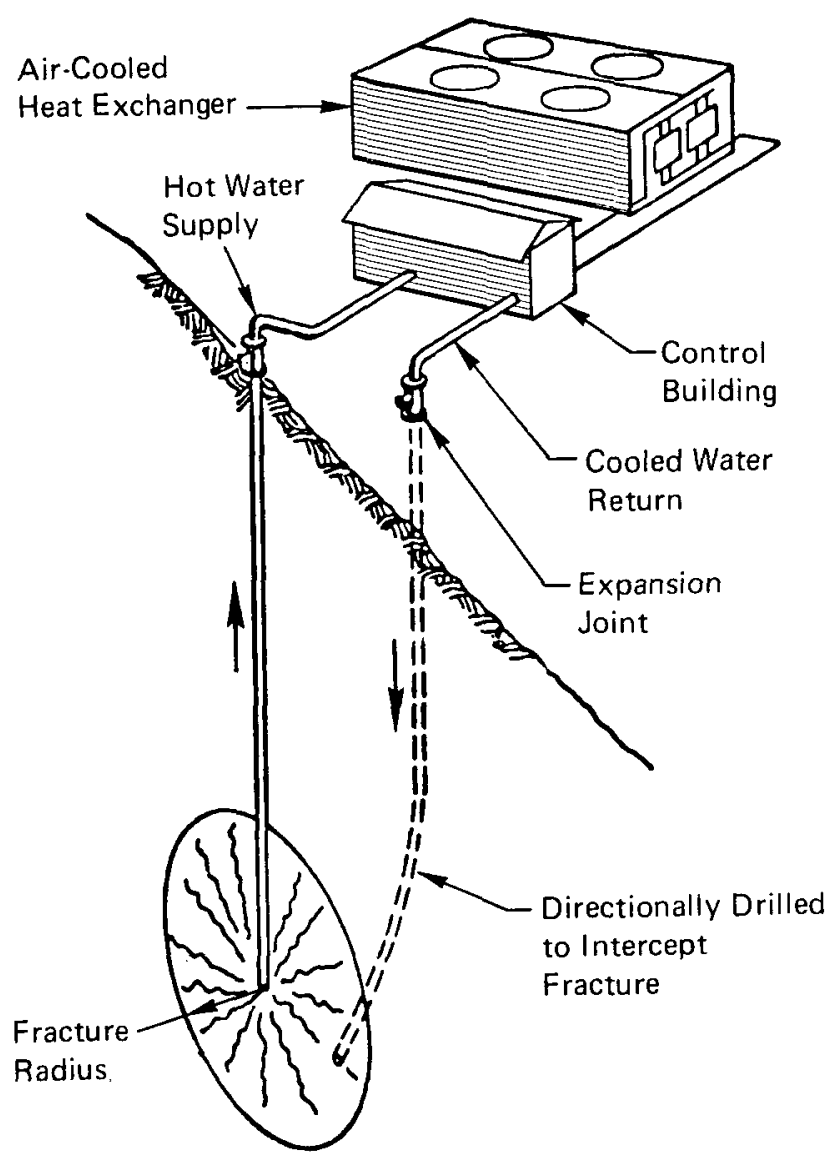

FIGURE 1.2 Schematic illustration of the hotdry-rock geothermal energy-recovery method.

primarily due to fractures and those where the porosity is mainly intergranular. This report concentrates mainly on the fractured porous and the nonporous hot-dry-rock resources, because the problems associated with nonfractured porous resources are largely extensions of those associated with the exploitation of hydrocarbon reservoirs, which fall into the subject area of another subpanel. Nevertheless, many of the problems outlined in this section do apply to this class of resource.

Until recently, rock mechanics, in its restricted sense, has not been widely recognized as a major contributor to geothermal energy exploitation. However, continuing development has focused a need for better understanding of the mechanical behavior of producing fractured and nonfractured reservoirs. Specific knowledge is needed of the interaction of pore-pressure changes and compaction and of the potential effects of compacting reservoirs on subsurface subsidence. An understanding of fracture mechanics is integral to the development of non-porous, hot-dry-rock resources. In a broader sense, a 
detailed knowledge of the physical and mechanical properties of rock masses, and their dependence on environment, is critical to the search for and evaluation and development of geothermal resources. Our present understanding of these areas is limited, particularly in the temperature and stress regimes applying in geothermal reservoirs.

In considering the recovery and development of geothermal resources the Subpanel concluded that the major overriding limitation caused by rockmechanics problems was the basic lack of understanding of their geology, geophysics, and mechanics. All phases of recovery of these resources, from exploration and evaluation to production and environmental impact, require a suitable conceptual and theoretical model for the reservoir. Part of the problem in identifying and refining these models iies in the complexity of natural rock systems and the gross heterogeneity of fractured rocks; part is the inability to gather more than highly localized data in a system buried under thousands of feet of rock. Other limitations are due to the technological problems of manufacturing sensing and production equipment to operate under the hostile environment of a geothermal reservoir. Although not strictly rock mechanics, this area is related to rock mechanics and is of sufficient importance to warrant inclusion in this discussion. These limitations will be considered in greater detail later.

Although many of the basic limitations are currently subjects of research, this research is sporadic, deals with small areas, and is generally insufficient to produce the necessary large-scale resource development. The basic recommendation, therefore, is that a coordinated and expanded research effort should be initiated in this area. Although the major limitations on the development of known and proven resources lie in the areas of production and development technology, the lack of full understanding of the geology and mechanics of these systems will severely limit the timely identification and development of new geothermal resources in the future and the development of known sites to full potential. The complexity of these characteristics will dictate intermediate to long-term research programs, and it is recommended that these should be initiated as soon as practical.

Given the imperfect basic understanding of many aspects of the geology and mechanics of geothermal reservoirs, detailed projection into the intermediate and long term is a hazardous, but necessary, exercise. It is strongly recommended, therefore, that many of the major research and deve1opment areas should be the subject of preliminary feasibility studies. These feasibility studies could be of one- or two-year duration, and could be fairly low-budget. items aimed at assembling all relevant current knowledge and pointing the way to the research necessary to remove the limitations.

Finally, the Subpanel strongly urges the continuation of interest and research effort into geothermal energy exploitation and development. Given sufficient effort to overcome the various problems, whether caused by geology, rock mechanics, or limitation in surface technology, geothermal resources form a potentially massive energy base whose exploitation would be environmentally acceptable. 
In view of the broad and diverse nature of the subject and the limited time available, it was thought to be neither possible, nor advisable, to detail completely the areas in which research is required. Thus the area of compaction mechanics, for example, has been identified as causing major limitations without detailing many of the problems and limitations that make up that area. To avoid inadvertent omissions the subject has been divided into six sections, each covering one phase of geothermal recovery, and each treated roughly in the same order as would be followed in resource development and exploitation: exploration, evaluation, drilling, stimulation, production, and environmental impact. These divisions are somewhat arbitrary and overlap in some areas, but they clarify the situation for the reader.

\section{Exploration}

Problems affecting exploration include the following:

- Imperfect characterization of geothermal resources in terms of exploration parameters

- Limited experience in applying deeper-sounding geophysical techniques such as deep-sounding magnetic and magnetotellurics to the identification of geothermal resources

- Lack of detailed knowledge of the effect of temperature on the physical, particularly electrical, properties of rocks

- Poor interpretive ability for detailed deep-sounding geophysical surveys

The search for commercial geothermal reservoirs depends mainly on the ability to recognize localities where high temperatures occur near the surface over an area sufficient for economical exploitation. Techniques exist, and are being perfected, that could be useful in obtaining this data on a regional basis. There is a growing understanding of the geological setting for potential geothermal sites, and existing geophysical techniques could be used for regional exploration. There remains, however, a need for better geological characterization of geothermal sites while potentially useful geophysical techniques are still in their infancy, particularly from the standpoint of interpretation.

For the regional identification of gross high spots, the use of deep magnetic techniques shows promise in identifying the depth of the Curie point, and hence in determining regional trends of this isotherm. In a more localized setting, magnetic, electrical, and particularly magnetotelluric techniques have a potentially significant role in exploration. These techniques suffer from imperfect knowledge of the dependence of rock properties on temperature and from poor characterization of geothermal sites. These shortcomings lead to limitations in interpreting data.

These techniques should be subjected to further research, and others should be sought and developed. This search should concentrate on techniques with a capability for deep surveying. Techniques that identify only surface abnormalities, or that identify only the first hot zone, are considered to be of limited application. 


\section{Evaluation}

Barriers to successful evaluation of geothermal resources include the following:

- Inadequate down-hole techniques for characterizing the rock away from the boreholes

- Inadequate characterization of fractured formations

- Imperfect understanding of the mechanics of recharge and poorly developed techniques for identifying and tracing recharge in wet reservoirs

- Lack of down-hole instrumentation for heat-flux and conductivity measurements

- Absence of electronic components capable of sustaining high temperatures for reasonable periods

- Lack of high-temperature resistant synthetic materials for use in down-hole tools

The first stage in the evaluation of a geothermal resource would be intimately connected with the later stages of exploration, and many of the same techniques and limitations would apply. Improved early evaluation is a natural fallout from research into exploration techniques, particularly that research aimed at understanding the temperature dependence of rock physical properties and the measurement and interpretation of these properties at the surface.

In down-hole measurements, adequate techniques are not available for identifying and characterizing fractured rock systems or any rock systems away from the immediate vicinity of a borehole. Several techniques might help. These include passive seismic monitoring, precise down-hole gravimetric surveys, and hole-to-hole sonic and electrical methods. A study of the relation of surface or regional structures and the down-hole determination of the primitive-stress-field orientation could help significantly. Advances in these techniques would help to evaluate and manage sites now under development.

From the standpoint of down-hole technology, the main limitations arethe poor high-temperature stability of electronic components and of synthetic materials used in down-hole tools. Many of the electronic problems can be and are being solved in the short term by the development of protected packages; eventually these problems will be overcome by the development of high-temperature stable components. Similarly the problems caused by synthetic material breakdown at high temperatures should be overcome with the continuing advance of this technology.

Further limitations were identified in the characterization of recharge for hydrothermal or steam reservoirs. Knowledge of recharge potential and areas will be essential in evaluating the availability of hot fluids and in the rational use of reinjection. Techniques currently under investigation to help in this characterization are based mainly on conventional hydrology and on the sophisticated analysis of water chemistry. These techniques, however, are not yet well understood, nor is their application to geothermal resources. This situation constitutes a major limitation to successful evaluation and management of existing reservoirs. 


\section{Drilling}

The problems of successful drilling are as follows:

- Temperature limitations on drilling equipment

- Scarcity of high-temperature lubricant-mud additives for lowpressure high-loss zones

- Underdeveloped technology for temporary sealing of high-loss fracture zones

Drilling technology, in itself a wide field that continues to receive much attention, has been the subject of similar workshops. Many of the limitations identified in drilling geothermal reservoirs are not specific to geothermal energy, and most would be solved by an evolutionary rather than a revolutionary process; in any case, they are dealt with more competently in other forums. For these reasons, no limitations have been specifically identified other than those peculiar to geothermal energy.

Stimulation

Hydraulic Eracturing

Rock-mechanics limitations to hydraulic fracturing are as follows:

- Imperfect understanding of the detailed mechanisms and controls for hydraulic fracture propagation

- Lack of effective techniques for mapping fractures

- Lack of suitable high-temperature proppant-carrying fluid

Hydraulic fracturing is a critical component in the development of unfractured hot-dry-rock resources. In this development, fractures are used to establish a connection between two or more boreholes, which requires an ability to predict fracture orientation and geometry, and to determine these parameters after fracturing. It is known that fracture propagation will be controlled by the stress field and by 1ithology, but little is known of the interrelation of these controls, and propagation in complex natural lithol-. ogies cannot be predicted. Even if these factors were understood, the limits imposed by reservoir characterization and in situ stress measurement would hamper their application. So far, despite considerable research, no successful techniques are available for mapping these fractures after their production.

These factors form a major limitation on the economic development of impermeable geothermal resources. Several different approaches to the problem are needed, including a basic theoretical and experimental study of fracture mechanics in natural geological materials under various states of stress, a study of the relation between major structural trends, the in situ stress and artificially induced fracture geometry, and a continuation of the studies of various geophysical techniques for fracture mapping.

The whole area of defining fracture propagation and of mapping fractures is difficult and complex, and it is imperative that a considerable, longlasting research effort be made to remove the major limitations imposed by the current state of the art. 
Other less extensive problems are the lack of suitable high-temperature tools, such as impression packers and borehole televiewers, for mapping fractures at the borehole, and the absence of suitable hightemperature carrying fluids for proppants. These problems are being addressed, and the work will probably continue under the impetus of current site requirements.

Exotic Fracturing

Progress is affected in particular by the following:

- Poor understanding of thermal cracking in geological materials

A technique such as thermal cracking will be essential for full development of a hot-dry-rock resource, because it will increase the volume of rock contacted by the heat transfer fluid. A general lack of information and understanding of the detailed development of these fractures exists.

Other exotic fracturing techniques that may be applicable to geothermal development are the electrical and explosive methods. Electrical methods may be useful in the development of controlled-fracture initiation. Although these methods could be of use in geothermal developments and should be monitored, they must take low priority as far as research support in this area is concerned. Explosive fracturing has possible application in the development of extensive-volume fracturing and in connecting blind holes to natural fracture systems, but this technique is 1 imited by the problems of developing explosives for use at the high geothermal temperatures and characterizing the fracturing produced. The desired results could probably be achieved in most cases by combinations of hydraulic and thermal fracturing, and for this reason explosive fracturing was assigned a low priority.

\section{Chemical Stimulation}

Although certain problems are identified in chemical stimulation, these are considered to be highly site-specific and to have limited overall impact. The limitations identified, therefore, are not considered to be applicable to the overall geothermal program, nor are they thought to be severe.

\section{Production}

The following are limitations to production of geothermal energy:

- Imperfect understanding of compaction mechanics of porous rocks and techniques to predict the behavior of these rocks when subject to varying pore pressures and temperatures

- Imperfect understanding of flow behavior in fractured reservoirs and the dependence of this on compaction and temperature

- Lack of monitoring instruments

The gross behavior of porous unfractured strata under varying pore pressures and temperatures is not completely understood. In fractured systems, even less is known, and flow characteristics are not well understood. The understanding available tends to be based on oversimple assumptions and to be restricted to isothermal and normal temperature conditions. The 
solution of these problems is essential to the controlled operation of a geothermal reservoir and requires a major, long-term research effort in the theoretical area, in the laboratory, and in the field.

Durable instruments, capable of monitoring production, need to be developed. Some of these instruments will be used to monitor pressure, flow rate, and temperature. Current techniques and instruments need upgrading to withstand the hostile down-hole environment. Others should be developed for monitoring conditions within the reservoir, particularly changes in water/steam horizons and recharge areas. In this latter group, considerable research is needed in developing techniques to be applied to both down-hole and surface instruments.

\section{Environmental Impact}

Knowledge of the environmental impact of geothermal development is restricted by the following:

- Very limited understanding of subsurface- and surface-subsidence mechanisms

- Inadequate understanding of seismic-hazard potential resulting from production and reinjection

- Lack of understanding of the impact of reinjection on the environment and on production in terms of physical, chemical, and mechanical changes

The boundary condition for subsidence will be reservoir volume changes induced by production, reinjection, and temperature changes. An adequate understanding of the compaction mechanics of the reservoir rocks is therefore an essential prerequisite for subsidence evaluation. Even with this knowledge, little is known about the behavior of the rocks overlying a compacting reservoir, particularly in areas where fault activation may lead to discontinuous subsidence. These gaps in present knowledge constitute a serious environmental limitation to geothermal production.

In view of the tectonically active localities of many potential geothermal developments, the imperfect understanding of the relations of fluid pressures to earthquake activation creates a major limitation, particularly where reinjection is contemplated.

\section{Summary}

The limitations identified in the preceding subsections fall into two distinct groups: the strictly rock-mechanics or geoscience-based limitations and those that are esentially technological with a strong bearing on rock mechanics in the broad sense. The limiting areas, and their relevance to different types of geothermal reservoirs, are summarized in Figure 1.3.

\section{RESEARCH PROGRAM}

\section{General Recommendations}

Although many of the most urgent problems in geothermal development are not concerned with rock mechanics, timely and extensive future development will require a much better understanding of the mass behavior and properties of 


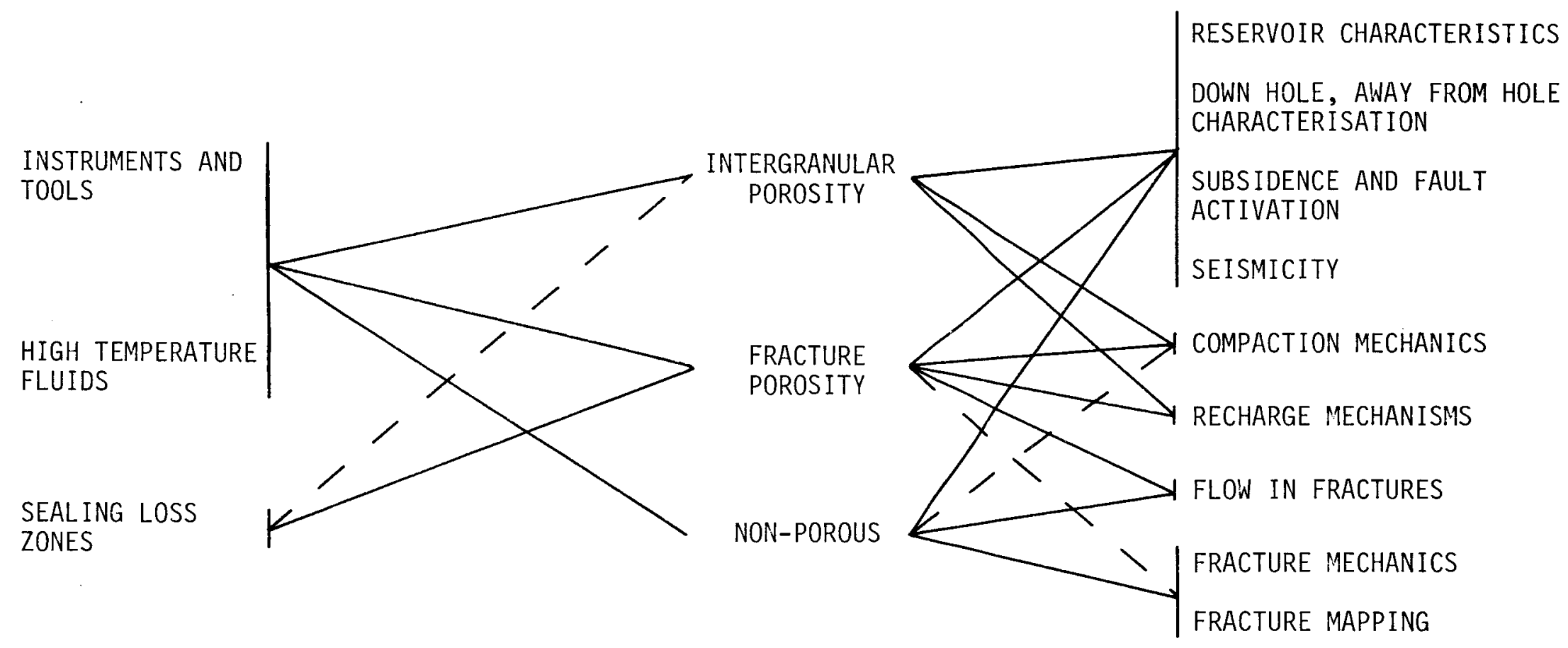

FIGURE 1.3 Relation of the various limitations to different classes of geothermal reservoirs. 
geothermal reservoirs and the overlying rocks. The current leve1 of know1edge in this area and the complexity of the problems involved demand a major research effort.

Assessing priorities for the various programs is difficult. Geothermal energy covers a wide range of rock types and production problems. Some programs are clearly most urgently needed in certain areas. In considering the limitations to the overall geothermal program, all rock mechanics research areas demand equal priority, whereas the various peripheral technological areas are of limited priority in the current study. They are undoubtedly important to the total geothermal effort but embrace research and development programs limited in nature, outside the area of the geosciences, and likely to be solved outside the geothermal program. These technological problems should, nevertheless, be kept in mind and their solution encouraged.

The Subpanel makes the following general recommendations:

- A comprehensive research program should be initiated immediately, for the purpose of removing the rock mechanics limitations to future geothermal development. This program should be initiated and continued with medium effort over a long period rather than with great effort for a short time.

- The program should be carried on in diverse research localities and by researchers with diverse backgrounds but with careful coordination by some central body.

- Adequate dissemination and interplay of the various research areas should be carried into other overlapping subject areas.

- Development in the various peripheral technological areas should be encouraged to improve down-hole techniques and equipment as soon as possible.

\section{Specific Recommendations for Research}

With these general purposes in mind the following specific research programs are recommended; the programs are divided into five major areas each containing several related programs. No priority is implied in the order of these programs. In certain programs an initial feasibility study is recommended. This study is envisaged as a one- or two-man-year, low-cost study, to define the state of the art in one particular area and to identify and evaluate the most promising lines of research.

Characterization, Identification, and Evaluation of Potential Geothermal Sites

- The characterization of the geological setting of commercial geothermal sites and the isolation of geological indicators that may help to identify future sites.

- An investigation of the influence of temperature on the physical properties of rocks from geothermal areas, particularly those properties that may apply to geophysical prospecting techniques.

- The development of geophysical techniques capable of identifying and characterizing geothermal sites, including development of both equipment and interpretation techniques. This program should be preceded by a feasibility study and should be closely related to the previous program.

- The application of existing and new geophysical techniques to geothermal sites, directed initially toward gaining experience in the use of 
present techniques and later toward evaluating techniques developed in the preceding program.

- The identification and development of down-hole passive and active logging techniques for the characterization of formations away from the immediate vicinity of the borehole, particularly in fractured reservoirs.

Characterization of Recharge in Wet Geothermal Reservoirs

- The investigation of recharge mechanisms by hydrological and geological interpretation methods and by flow studies.

- The development of techniques for identifying recharge areas and geothermal fluid provenance. This development should be preceded by a feasibility study.

The Mechanics and Characterization of Artificial Fracturing

- An investigation of the influence of stress and lithology on fracture propagation and orientation and the development of mathematical techniques for predicting this influence.

- An investigation of known geological structures as possible indicators of preferred orientations or induced fractures.

- The development of techniques for determining the down-hole triaxial stress field.

- The development of techniques to be used for mapping fractures. This development should be preceded by a feasibility study.

- An investigation of thermal fracturing in stressed rocks and the development of mathematical techniques for predicting this.

Compaction, Thermal Mechanies, and Flow Studies

- The evaluation of existing theories for the behavior of porous rocks under elevated and varying pore pressures and temperatures, upgrading and extension of these theories, and development of new models where necessary.

- The development of theories and models for the behavior of naturally fractured rocks under elevated and varying pore pressures and temperatures.

- An investigation of fluid flow in natural fracture systems undergoing compaction and the development of theory and models to predict this flow.

\section{Environmental Impact Studies}

- The development of models for the behavior of rock masses above compacting reservoirs, including those where fault activation is possible. The models are to be based on data for rock properties and are to be evaluated against known areas of subsidence.

- An investigation of the effect of fluid pressures and of temperature on seismic activation in geothermal areas, with particular reference to reinjection.

\section{CONCLUSIONS}

Limitations imposed by rock mechanics on geothermal development have been identified in the areas of exploration, evaluation, drilling, stimulation, production, and environmental impact. These limitations arise from major 
gaps in the present understanding of the nature and mechanics of geothermal reservoirs, together with some peripheral problems in technology caused by the hostile environment in a geothermal reservoir.

These limitations do not form absolute barriers to the current development of geothermal resources, but they will severely curtail future development. They form absolute limitations to the rapid, economic, and efficient development of a major, environmentally acceptable source of energy to its full potential.

The Subpanel recommends that a medium-level, long-term research program be initiated immediately to start to determine many of the unknowns in geothermal-resource exploration and production. Although this program should draw on diverse research talents, it should operate as an integrated unit by central coordination. The program should include concurrent efforts in the areas of site characterization and identification, recharge characterization, fracture propagation and orientation, compaction and thermal mechanics, fluid flow in fractured media, and subsidence and seismic hazards evaluation. Development of down-hole equipment and techniques capable of withstanding the harsh geothermal environment should also be encouraged.

In summary, geothermal energy forms a potentially massive resource for this nation, but the nature and mechanics of the reservoirs are poorly understood. It is imperative that this imperfect understanding be subjected to a large, well-coordinated research program now, if this resource is to reach its full potential in the future. 
0

0 


\section{MINING AND IN SITU RECOVERY}

Hilmar A. Von Schonfeldt

Subpanel Chairman

\section{INTRODUCTION}

The objective of this Subpanel was to determine rock-mechanics limitations to mining and in situ recovery of energy resources. These limitations are defined as barriers that prevent a successful and economic recovery of our energy resources. Although economic issues were not discussed, it was understood that technology and economics are inseparable.

The potential contributions of rock mechanics in conventional mining are still not fully recognized. They fall into the areas of safety, economics, and conservation. Such contributions will be more cost-effective than any advances in in situ mining technology for at least the next decade; the economic impact of in situ mining will remain relatively insignificant to the end of this century.

In situ mining technology is still in its infancy. Certain rock-mechanics limitations determine whether mining of a specific deposit by an in situ method will ever be economically feasibie. These limitations are in the general areas of permeability control and ground control.

\section{ROCK-MECHANICS LIMITATIONS TO}

MINING ENERGY RESOURCES BY CONVENTIONAL METHODS

Conventional techniques can be applied to mining coal, uranium, oil shale, and tar sands. Rock-mechanics limitations exist at present in the area of poor backfill techniques, prediction and control of rock bursts and coal bumps, slope stability in deep open pits, materials handling, methane control, environmental impact, and the need for large barrier pillars that represent a loss of 50 percent of the coal amenable to conventional mining. These are broad areas requiring more detailed problem definition than is within the scope of the present report. Reference is made to studies on the research needs of mining, such as those conducted by the University of Utah under USBM Contract No. J0155143 (principal investigator: W. A. Hustrulid), A Study to Determine Research and Development Needs in Western Mining. 
Similar studies have been made or are being made by the Pennsylvania State University (principal investigator: R. Stefanko), and the University of Missouri, Rolla (principal investigator: J. Scott). A further study of research needs in mining was the subject of a workshop held in Minnesota in 1975, chaired by Charles Fairhurst and sponsored by the National Science Foundation. The report of this study is in preparation.

\section{ROCK-MECHANICS LIMITATIONS TO IN SITU ENERGY RECOVERY}

In an attempt to define rock-mechanics limitations to in situ recovery of energy fuels, the various kinds of deposit and the type of in situ recovery process have to be considered. Two examples are shown in Figures 2.1 and 2.2 .

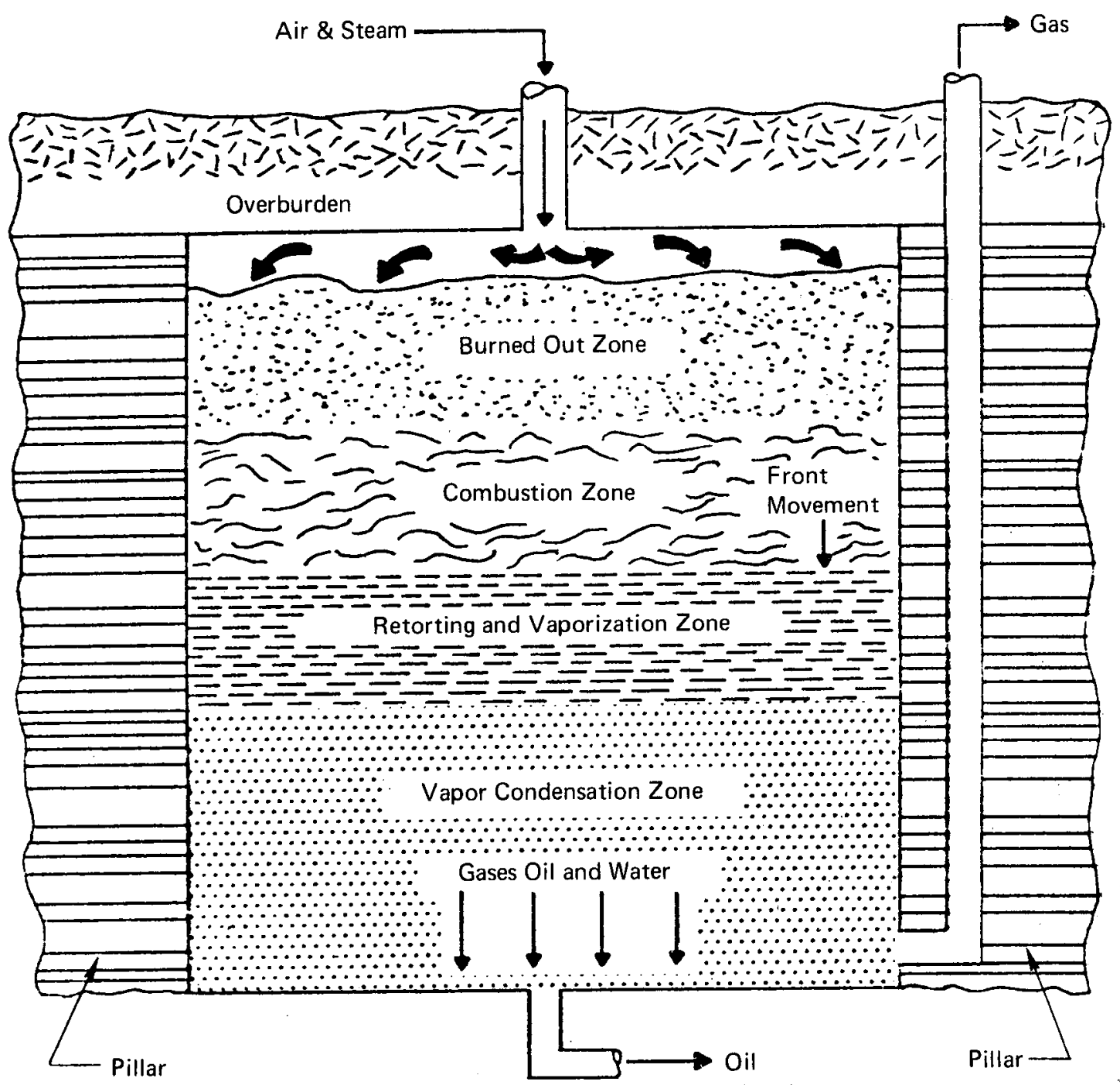

FIGURE 2.1 Idealized schematic of in situ recovery with burning from top. 


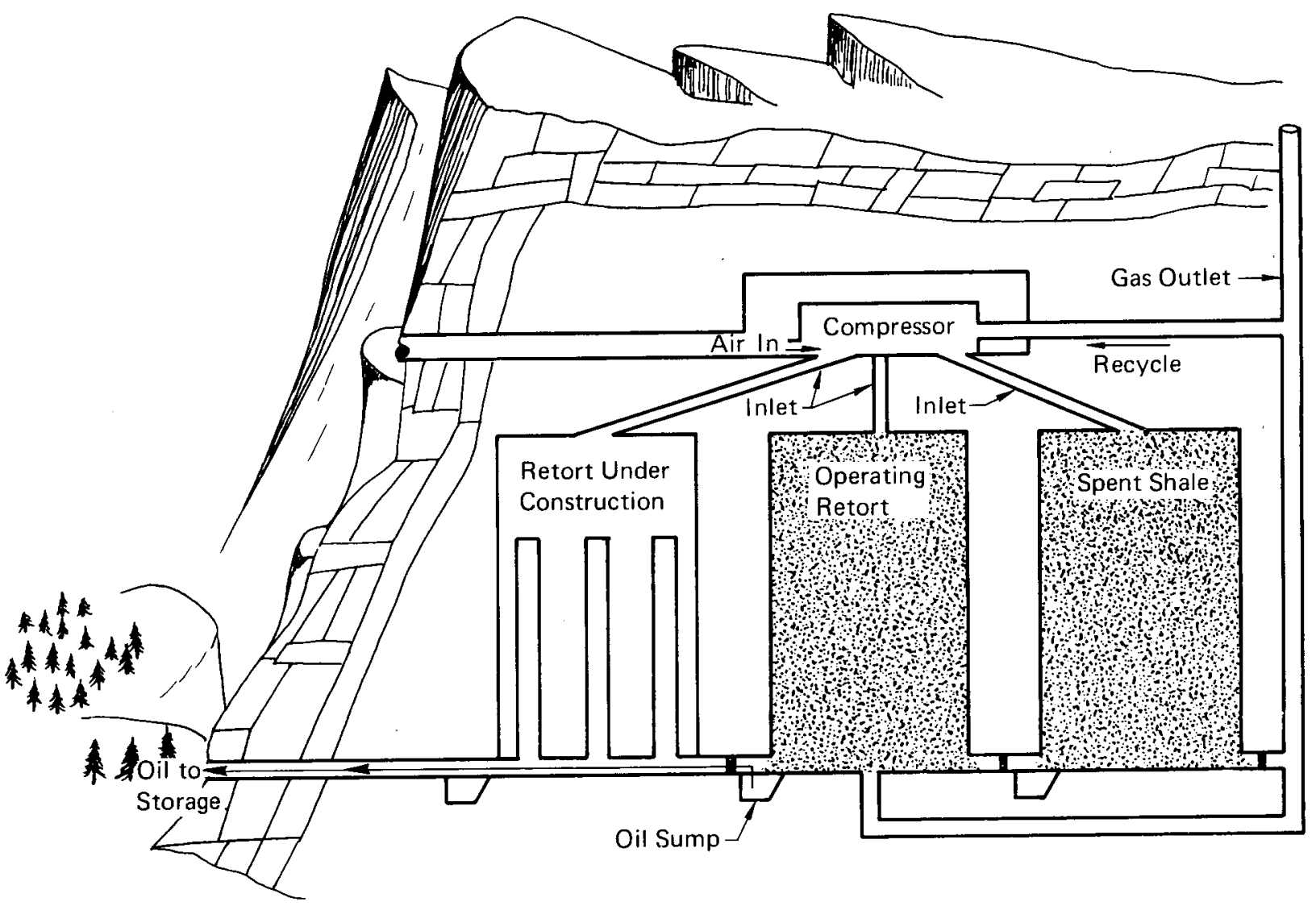

FIGURE 2.2 Schematic cross section of large in situ process for illustrative purposes.

Most uranium deposits under consideration for in situ mining within the United States occur in relatively permeable sandstones. Fluid-flow problems are encountered in the recovery of uranium through leaching. For this reason, in situ recovery of uranium will not be considered in this report. It is recognized, nevertheless, that certain problems involved in the in situ recovery of uranium pertain to rock mechanics; some of these problems, such as directional drilling, are common to other resources, and their explanation need not be duplicated.

This discussion will pertain largely to the in situ mining of coal, oil shale, and tar sands.

Al1 processes of any practical. consequence require control over permeability. In massive tight reservoirs, such as oil shale or possibly thick coal seam, positive control and efficient recovery. of the available resource may require large areas of the deposit to be "rubblized." It is important that this rubble zone consist of fragments of a size and uniformity required by reaction-zone kinetics and production rates. Little practical technology exists at present in the area of rubblization other than certain techniques that combine standard mining methods with in situ processing. 
A second area of permeability control concerns the establishment of high-permeability communications channels in predetermined directions. Considerable experience and knowledge already exist in hydraulic fracturing technology.

Permeability generation and control, in particular rubblization technologies, thus represent fundamental rock mechanics limitations.

A second such limitation exists in the area of ground control, which may be divided into the problems of immediate roof control and overburden subsidence control. Any process that results in the removal of a substantial amount of material, such as in coal gasification, will create large voids underground. Premature caving of the roof in these voids may slow or extinguish the recovery process. The control of the entire overburden, including water-bearing formations, is poorly understood. Both areas are critical to any commercial-scale in situ operation, especially where high and extensive voids are created.

To overcome both of these limitations, we need to develop a much better understanding of the behavior of rock. Although we do not intend to provide a detailed list of research projects for the removal of the above-mentioned limitations, it may suffice to say that of the large amount of rock-mechanics data that exists already, very little is directly applicable to the solution of the problems to be solved. Fundamental rock-mechanics research is required that continually takes into account the application of the research to advance the state of the art.

Other rock-mechanics 1 imitations for energy-resource recovery through in situ mining techniques occur in the area of drilling technology and in methods of site characterization. In particular, improved directional drilling capabilities, remote-measurement and monitoring techniques, as well as improved modeling and data-interpretation methods, are of great importance to commercial-scale operations. Important aspects in these areas, such as the development of drilling motors or instrumentation, are not, however, specifically related to rock mechanics.

\section{RECOMMENDED RESEARCH AND DEVELOPMENT PROGRAMS}

Permeability control and roof control are considered to be two critical problems that must be solved before a successful in situ recovery of coal, oil shale, and tar sands can be achieved. Without intending to define any specific projects, the group concluded that the research should address such questions as the following:

- The effect of elevated temperatures on (primarily sedimentary) rocks

- The effect of high loading rates in the explosive range on rock

- The effect of stress and temperature on permeability

- Ductile fracture mechanics

- Behavior (creep, consolidation, support strength, permeability) of the material left in place (the residue)

\section{CONCLUSIONS}

Within the next 5-10 years, significant improvements can be expected in drilling equipment and remote control. Industry and equipment suppliers 
have recognized the need for better directional and large-hole drilling and are working on improving equipment. The role of rock mechanics in this area is to optimize the effectiveness of such equipment rather than to remove technological barriers.

Remote sensing and improved modeling techniques are important in increasing the efficiency and profitability of commercial-scale operations. New methods that apply radar technology to remote sensing through rock are being explored, and seismic techniques are constantly being improved. More effective methods in this area, as well as improved modeling techniques, are needed within the next decade or two. Because huge capital expenditures will be committed to specific sites, it is essential that proper evaluation techniques be available before such commitments are made.

The most severe rock-mechanics limitations at present are poor control over the permeability of the resource rock and over the behavior of the ground surrounding the resource. One of the main reasons for these limitations is our lack of understanding of the basic mechanics of rock at elevated temperatures in the presence of flowing liquids and gases. 
$\ominus$ 
INUCLEAR-WASTE DISPOSAL

Wolfgang R. Wawersik

Subpane 2 Chairman

\section{INTRODUCTION}

The future of commercial nuclear-power generation is partly dependent on the existence of an acceptable program for the safe management of radioactive wastes from fuel-cycle operations. In addition, military programs will continue to generate considerable quantities of radioactive waste that cannot be held indefinitely in interim storage or near-surface facilities but must be removed to safe terminal-storage sites. For these reasons, since about 1957 the U.S. Government has been studying a number of waste-disposal concepts, and, in 1976, it announced a greatly expanded and accelerated program for the management of nuclear waste under the direction of the Energy Research and Development Administration [ERDA, now a part of the Department of Energy (DOE)]. This program calls for the excavation of several waste repositories in deep land-based geologic formations during the next 12 years. Specifically, DOE plans to develop a Waste Isolation Pilot Plant in the salt beds of the Delaware Basin in southeastern New Mexico, which is to receive transuranic (non-heat-generating) and solidified intermediate-level (heat-generating) radioactive wastes from military programs, beginning in 1983 (Figure 3.1). In addition to this facility, DOE intends to provide for six additional terminalstorage plants, between the years 1985 and 1989 , for commercially generated waste consisting of low-level transuranic waste, fuel cladding waste, and solidified high-level wastes. On the basis of past research and development efforts, it is likely that the first two of these latter repositories will be located in salt formations. Subsequent repositories might be located in nonsaline rocks, such as shales, crystalline rocks, or basalts or in selected carbonate rocks.

Now that deep geologic formations are being considered for the containment of nuclear waste, rock mechanics becomes an integral part of the waste-management program, which poses two essentially new problems. The procedures for geologic site selection and repository design must not only ensure waste isolation for thousands of years but must also assess the short- and long-term effects of elevated temperatures due to the emplacement 


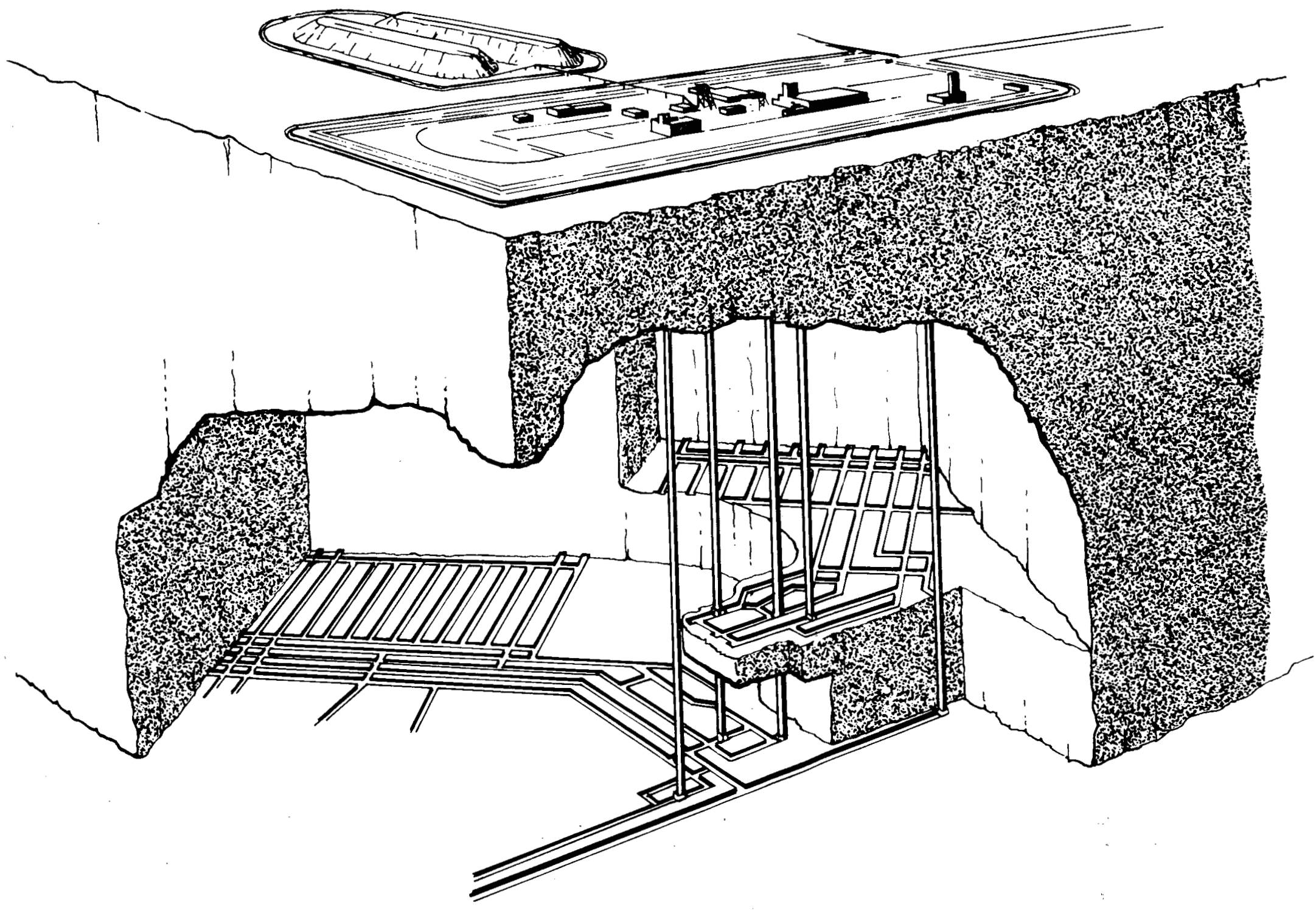

FIGURE 3.1 Artist's schematic of a conceptual Waste Isolation Pilot Plant (WIPP) in the salt beds in southeastern New Mexico. Cutaway of underground facilities shows five shafts; a 650-m level including shaft stations, entry ways, and storage rooms for transuranic contaminated waste; and an ofo-m level for storage of intermediate- and high-level wastes. 
of heat-generating radioactive waste. Both of these problems are without precedent in the history of the construction of deep, underground excavations and require that limitations of the existing rock-mechanics technology be identified and resolved early during the development of nuclearwaste repositories.

\section{SCOPE OF SUBPANEL DELIBERATIONS}

Recognizing the need for the acceptable disposal of nuclear waste from both commercial and military sources within the next 8-10 years, the Subpanel on Nuclear-Waste Disposal chose to review and identify only those rock-mechanics problems that arise in the development of nuclear-waste repositories in deep land-based geologic formations using conventional mining techniques. Alternatives are being evaluated. For example, work is being funded by the Department of Energy (DOE) on the emplacement of radioactive waste in ocean sediments. Alternatively, considerations are discussed in the literature concerning the disposal of high-level nuclear waste in deep drillholes. Radioactive decay heat would melt the rock surrounding the waste and ultimately produce a solidified mixture of rock and waste products. Efforts to develop some of these disposal concepts should continue. In the opinion of the Subpanel, however, it will be impossible to implement fully any of these alternatives by 1985 .

\section{DEFINITION OF ROCK-MECHANICS PROBLEMS}

\section{IN THE DEVELOPMENT OF NUCLEAR-WASTE REPOSITORIES}

Rock mechanics relates to four aspects of nuclear-waste disposal: (1) The identification of geologic formations that by virtue of their location, structure, petrography, thermomechanical, and chemical properties are promising long-term containment media. (2) The structural, hydrologic, and stress-field characterization of specific sites in candidate rock formations before massive excavation. (3) The site-specific design of nuclear-waste facilities, including the design of excavation methods, size and geometry of mine openings, waste-emplacement patterns, and backfilling procedures. This design must ensure that the facility will remain stable during its operational life, either directly or through parallel developments of remedial measures, and that the ground will remain mineable beyond the waste-emplacement phase to make waste retrieval possible. Furthermore, given an understanding of the chemical stability of all waste forms and of radionuclide transport mechanisms, the design must ensure that the geologic barrier between waste and biosphere remains intact. (4) Establishment of geologic and hydrologic baseline data prior to mining, as well as monitoring of the waste repository to evaluate the long-term effects of mining and waste emplacement and to define safe retrievability periods.

The Subpanel reviewed the major limitations that exist in each of the foregoing categories of applicable rock-mechanics activities. Because ultimately each aspect considered will be of comparable importance, the Subpanel adopted the topical order most likely to coincide with the actual project sequence during the development of each radioactive-waste facility. 
Rock formations qualifying for nuclear-waste disposal must have and retain low permeabilities and possibly high sorption potentials for radionuclides to ensure the long-term isolation of radioactive waste. From the viewpoint of rock mechanics, these criteria can be applied only if the influence of rock porosity and of discontinuities in rock masses on the flow of fluids can be evaluated. Furthermore, they require that all thermally induced effects on the long-term response, and therefore on the fluid transmissibility of rock masses, be known. Existing data concerning the mechanical, thermal, and chemical properties of rock masses are insufficient to make such evaluations. A major experimental research and development effort is therefore recommended. Because generic sorting of the relative containment potential of different geologic formations requires less detail than that which is needed for formation and site-specific design, much of the proposed research and development effort can be performed in the laboratory. Furthermore, most of the basic material properties needed can be gathered in separate experiments on competent rock and on discrete fractures. Competent-rock properties needed should include at least stress-strain behavior as a function of effective stress state, temperature, time, and loading rate, porosity, and permeability, as well as time- and temperature-dependent fracture and hydrofracture potential. Combined with such experiments, thermal properties and mineralogical and chemical alterations should be determined and efforts directed toward the identification of pronounced coupling between all governing thermomechanical rock properties.

Parallel to tests on competent rock, work should proceed to define the thermomechanical response of generic fracture types, e.g., cleavage and shear fractures, to establish the relation between the thermomechanical and chemical fracture behavior on one hand and fracture permeability on the other. This experimental work should provide at least realistic upper and lower bounds for the permeability of discrete fractures in saturated rock for a reasonable range of temperature, stress, and water head. In all fracturedrock experiments, the possibility of scale effects should be anticipated. Recent fluid-flow measurements on fractured-rock samples up to $1 \mathrm{~m}$ in diameter strongly suggest that a scale effect is present and that the results from conventionally sized cores $(5-15 \mathrm{~cm})$ are somewhat conservative.

\section{RECOMMENDAT IONS}

\section{Site Characterization}

It would be ideal if site characterizations in favorable geologic formations could provide a complete and unique set of structural and hydrologic data from surface measurements and boreholes without shaft sinking and subsequent underground development work. It would also be desirable to establish the in situ stress state from deep surface boreholes alone and to obtain representative rock-mass cores, which, in addition to borehole experiments, would suffice to determine the bulk thermomechanical rock-mass behavior. The ultimate objective would be to complete the total design of radioactive-waste repositories before construction commenced.

Only some of these ideal goals are possible by means of today's exploration technology on a local as opposed to a regional geologic scale. Most important, available methods for surface and borehole exploration do not 
necessarily identify localized anomalies such as gas or brine pockets in salt formations over appreciable distances. Similarly, the methods are inadequate to determine the details of partings, fracture systems, or irregularly distributed but sizable shatter zones, all of which frequently control the hydrologic regime of nonsaline rock masses. In fact, several routine exploration tools are so limited that it is not easy to distinguish between highly permeable and largely impermeable fractures at the walls of boreholes without resorting to nonroutine tests such as multiborehole fluid injection and tracer experiments.

Less severe, but still significant, limitations exist in the ability to measure in situ stresses at depth, even after mining has begun. To date, hydraulic fracturing constitutes the only viable method for deep-hole stress measurements, provided that certain assumptions concerning the in situ tensile strength of rocks and the principal directions of the in situ stresses are valid. All other stress measurement techniques are either limited to relatively short distances from accessible free surfaces, or they invoke generally unrealistic constitutive relations for rocks to convert strain or deformation readings to stress.

The third principal limitation for complete site characterization prior to mining lies in the inadequacy of present-day procedures for borehole sampling of rock masses. Because detailed structural characteristics of rock masses cannot yet be resolved over appreciable distances, it is not clear whether cores from boreholes can expose all relevant features. Furthermore, existing drilling technology does not usually yield complete core recovery, and, finally, doubts prevail as to whether the thermomechanical properties of relatively small core samples are representative or sufficient to predict the in situ rock behavior because of unresolved scale effects.

Although it is beyond the scope of this Subpanel to make specific recommendations for work that might help to overcome existing deficiencies in site characterizations for radioactive-waste repositories, we strongly recommend that the following broad directions be explored:

- On the basis of case studies of mining and large underground-construction projects, statistical techniques should be developed to describe fracture systems including apertures, fracture-surface characteristics, fracture extent, density, orientation, and connectivity.

- New borehole-exploration techniques, such as microwave and radar techniques, gravimetry, acoustic holography, and photogrammetry should be considered to delineate fracture systems, and the penetration potential of these methods into the walls of boreholes should be assessed.

- Surface-to-borehole and borehole-to-borehole measurements should be considered in addition to pumping and fluid injection tests, which are already in use. Because such measurements are likely to provide indirect indicators for average rock-mass structures, the uniqueness, e.g., for varying water contents of any one or combinations of such measurements, should be evaluated.

- The use of angled exploration holes, including multiple whipstocking should be considered.

- Present efforts to perfect in situ stress measurement techniques should not only be intensified but also more effort should be devoted to realistic analyses of rock-mass instrument interactions. 
- The technology for fracture deformation and mechanical-properties testing in boreholes should be advanced and combined with hydrologic testing where possible.

- The design and construction sequences of waste repositories should provide for extensive underground site exploration, particularly in nonsaline rock masses.

\section{Site-Specific Design}

Because of the long time scales involved, and because of thermal considerations, the design of radioactive-waste repositories cannot rely exclusively on conventional mining and excavation experience. Within limits, such experience can provide guidelines for the development of transuranic-waste disposal facilities. However, it does not render an adequate data base for forecasting the effects of heat-generating wastes. As a result, the Subpanel sees no alternatives to the use of analytical design procedures, large-scale independent hot-waste simulation experiments, and the adoption of the concept of retrievability for yet undefined but probably site-dependent periods.

Within the context of rock mechanics, analytical repository design implies the use of numerical or hybrid computer codes to predict rock temperatures, stresses, deformations, stress- and temperature-induced fracturing, effective fracture and rock-mass permeability, brine migration in salt, and groundwater flow in fractured rock. Furthermore, such computations must deal both with near-field effects that influence pillar stability and maximum permissible rock temperatures, for example, and with far-field effects and their impact on groundwater movements.

A considerable number of general and special-purpose computer codes now in existence are suitable or adaptable in principle to perform the required analyses. At this time, however, serious questions exist concerning the predictive capabilities of these codes. Besides limitations in site and stress-field descriptions, which are bound to reduce design accuracies, some conceptual uncertainties remain: It is not clear whether rock masses should be defined as continua, composites with quasi-continuum properties, or assemblages of structural elements, all of which have to be modeled discretely, at least in near-field analyses. In addition, the site-specific thermomechanical constructive relations, fracture and flow conditions now in use for rocks, fractures in rock, and even for rock salt are largely unproven and possibly inadequate for the task of long-range extrapolation. Finally, the Subpanel recognizes the shortage of systematic attempts to integrate experimental work, constitutive modeling, and code calculations to validate each step within this cycle of activities and, therefore, to assess the reliability of analytical design procedures. Although it may prove impossible to reproduce in all instances the high degree of accuracy of thermal calculation in rock salt, efforts must be intensified to establish maximum error bounds of results, or statistical error bounds, which are defined in terms of the distribution characteristics of all code input data.

Because of the number of listed and implied limitations in site-specific repository design, the Subpanel recommends that major research and development efforts be undertaken in the following areas: 
- Material-properties determinations, which in details and scale go beyond the more qualitative tests needed to identify candidate rock masses for the disposal of heat-generating radioactive waste. The availability of suitable experimental facilities and the adherence to standard experimental procedures should be ensured to permit comparisons of data from different sources.

- Development of realistic temperature- and time-dependent constitutive relations, fracture, and flow rules. This work must be conscious of scale effects and consistent with existing code options to treat competent rock and fractures in rock masses discretely or by way of averaging procedures (quasi-continuum or continuum models).

- Laboratory and bench-scale studies in which numerical simulations of independent experiments are used to test the validity of constitutive models and the sensitivity of results to particular parameter variations, such as mean stress or load path.

- Parametric excavation, waste, and backfill simulation calculations to evaluate the sensitivity of stress, deformation, and permeability predictions to changes in in situ stress states, temperature, fracture density, and fracture orientation. These calculations should include comparative two- and three-dimensional analyses to provide insight into the limitations of two-dimensional analyses in the simulation of the effects of excavation and waste-emplacement sequencing. These same parametric studies should also be used to identify the most suitable numerical codes and to delineate the need for coupled analyses.

- In situ experiments on the scale of Project Salt Vault are considered mandatory. In such experiments the possibility of inducing large-scale failures, both structurally and thermally, should be seriously considered, to assess the full range of the predictive capabilities of design analyses and to provide realistic criteria for the definition of permissible stresses, deformations, temperatures, and fluid-flow rates.

- Surveys of case studies to evaluate the potential of back-calculations of fractured-rock response and groundwater flow.

- Assessment and development of possible preventive or remedial actions, such as grouting to control groundwater movements.

\section{Site Monitoring}

Considering the state of the art in the identification of candidate geologic formations, site characterization, and repository design, monitoring problems of disposal areas are likely to be less urgent for the near future. The Subpanel believes, however, that the concept of waste retrievability and the current indeterminacy of retrievability periods will require a strategy and a technology for site monitoring. For this reason, the Subpanel suggests that at least the strategy for this effort be established as soon as possible, to guarantee the availability of baseline data that can serve as reference for future monitoring activities. Reference data concerning the following subjects should be obtained: surface and subsurface hydrology, including water age and chemistry; geologic structure; regional seismicity and microearthquake activity; in situ stresses; and temperature regime. It is also recommended that suitable instrumentation be developed to monitor all reference parameters over a long time. 


\section{CONCLUSIONS}

Rock mechanics constitutes an integral part of all phases of development of nuclear-waste repositories in deep land-based geological formations: identification of candidate formations, selection of specific geologic sites, actual repository design, and ultimately, site monitoring. Overall, the application of the existing rock-mechanics technology is limited by the behavior of geologic formations and of hydrologic regimes that must be predicted for conditions of elevated temperatures and for thousands of years. Both requirements are without precedent and can be relaxed only if other reliable containment mechanisms are identified, for example, radionuclide sorption through ion exchange. For the same reasons the Subpanel concurs with DOE pians for the design and construction of nuclear-waste repositories to incorporate the option of retrievability for some period.

Considering disposal problems of non-heat-generating and heat-generating nuclear waste separately, the Subpanel is confident that non-heat-generating radioactive waste can be isolated safely from the biosphere by means of conservative applications of existing rock-mechanics and construction technologies. As an added safety measure, the Subpanel recommends that appropriate mine- and surface-monitoring systems be employed to demonstrate that such facilities are satisfactory.

Present rock-mechanics technology is not sufficient to predict the full range of thermal effects on site containment caused by the emplacement of heat-generating radioactive waste. The Subpanel believes, however, that the improvements in technology needed to make such predictions within defined and acceptable bounds of accuracy can be acquired with the proper research and development effort in the following broad areas:

- Determination of the thermomechanica1, time-dependent properties of candidate rock masses and establishment of realistic constitutive relations considering all effects that might bear on the movement of fluids.

- Identification and description of fracture zones, fracture networks, and anomalous inclusions in rock masses; the use of statistical methods in this area should be advanced.

- In situ stress measurements.

- Validation studies of design procedures and analyses ranging from laboratory studies to large in situ experiments.

- Site-specific parametric analyses of facility concepts. The significant parameters include in situ stress state, thermal loads, rock-mass properties, fracture geometry, groundwater regime, and facility geometry.

- Development of a strategy for site monitoring and acquisition of baseline data.

- Development of instrumentation capable of monitoring in situ changes for long periods in an adverse environment. 


\section{OIL AND GAS RECOVERY}

Henry J. Ramey

Subpanel Chairman

\section{INTRODUCTION}

Exploration for oil and gas proceeds ideally from the large to the small. Prospective regions are identified, based on the occurrence of source, trap, reservoir, and seal. In a new area in which no wells have been drilled, remote sensing and surface geological mapping provide the only information. Remote sensing includes LANDSAT imagery, gravity, magnetic, geochemical, and seismic surveys. All knowledge of prospective targets derived ahead of the drill bit comes by inference and analogy. On the basis of the available data, specific targets are selected for drilling. Up to this stage, understanding of the mechanical characteristics of rock and rock-fluid systems is most useful in eliminating certain targets as nonprospective because of unfavorable reservoir or seal characteristics. For example, there are certain absolute limitations on the preservation of porosity with depth, and without a porous container hydrocarbons cannot accumulate. A certain minimum thickness of salt or other dense cap rock may also be necessary to ensure that accumulated hydrocarbons have not dispersed over geologic time.

\section{LIMITATIONS IMPOSED BY ROCK MECHANICS ON OIL AND GAS EXPLORATION}

Exploratory drilling has unique problems not usually associated with development wells. Little is known of the mechanical properties of the formation to be penetrated in reaching the target horizon or of pore fluid pressures. This makes the choice of drilling-mud weights and casing programs particularly difficult. This is especially true in deep-water drilling, because the weight of the column of water overlying the seafloor ensures that pore pressure will be high. Thus, only a small difference exists between the mud weight required to control the formation pressure and that which would break down the formation and cause lost circulation.

By drilling a well, the explorationist gets a first direct look at the rocks in the subsurface-cores and cuttings. Deductions about porosity and lithology may be made from logs. Strictly speaking the new information reflects only the properties of those rocks in the immediate vicinity of the 
well bore, and when making inferences one must take into consideration whether the dri11 core is representative of the entire section. Improved means of interpreting logs, especially to locate fractures or evaluate lithologically heterogeneous formations, are continually being sought. Drill stem or production tests, properly interpreted, can provide information about a larger volume within the hydrocarbon reservoir。

Down-hole information can be used to confirm or refute hypotheses about source, trap, reservoir, and seal that are based on remote information. often a single item of data can be interpreted in several ways; a unique model of the prospect can be constructed only by considering many items of data simultaneously. The earlier a working hypothesis or hypotheses can be constructed, the more likely will it be that additional attempts to characterize the resource proceed in an efficient and orderly manner.

\section{DRILLING PROBLEMS RELATED TO ROCK MECHANICS}

Drilling rate is a complicated function of many factors: rock properties, mud properties, hydrostatic pressure at the bottom of the hole, and the pore pressure in the formation below the bottom of the hole. A high differential pressure between the mud at the bottom of the hole and the pores in a permeable formation below results in chips being plastered back on the bottom of the hole as soon as they are formed. Even with a nonpermeable formation, a high hydrostatic pressure at the bottom of the hole changes the stress components in the rock as the rock bit tooth penetrates and may, with a weak formation, render it so plastic that chips are not formed.

These factors are recognized in oil and gas drilling, and the bottom-hole pressures are generally carried as low as safety permits. In fact, air or gas is used as the circulating fluid when possible. The use of jet bits that direct high-velocity mud jets to the bottom of the hole helps to reduce the adverse effects of the high bottom-hole pressure.

Other methods have been proposed. One method involves the use of a double-walled drill string in which drilling is done through a packer above the bit. The drilling mud is sent down the annulus between the two strings, and the returns come up the center hole. Another method maintains a high average pressure at the bottom of the hole but varies this pressure with acoustic devices so that, during each contact of a bit tooth, there is at least one period of low pressure. This method has been discussed in U.S. Patent 3441094, awarded to Galle and Woods, but so far neither of these ideas has been successful. Continued study should be made on the problem of high pressure at the bottom of the hole.

The most common rock bit is a three-cone bit with cutting elements of either steel or tungsten carbide. In certain applications, particularly in directional drilling, diamond bits are more economical, because they drill by scraping rather than by penetrating the surface. New or improved drilling bits are continually being developed and evaluated by industry.

Other problems are related to the maintenance of a satisfactory hole wall and avoidance of lost circulation and blowouts. These problems are important, but at present it appears that they are being handled efficiently by industry (Ad Hoc Committee on Technology of Drilling for Energy Resources, 1976). 


\section{FORMATION EVALUATION}

Inability to evaluate hydrocarbon resources early and reliably during drilling and well completion limits resource development and recovery. Frequently, conventional we1l-logging methods fail to detect hydrocarbon-bearing intervals. In addition to development of better devices and interpretative methods, the operating range of present devices needs to be extended. Deeper drilling means higher temperatures and pressures and the need for high producing rates to justify the increased investment in a deep well. High producing rates can lead to mechanical buffeting of certain wire-line devices (pressure-temperature recorders). High temperatures may destroy electronic circuitry in the logging tool itself. There can also be problems with the insulating materials in wire-line cables that are used to suspend devices in a well。

The vague and uncertain response of well-bore logging devices to hydrocarbon-bearing formations creates a major problem in resource assessment.

\section{RESOURCE ASSESSMENT}

The key to resource assessment is early estimation of the bulk volume of a reservoir, the porosity, the fluid content of the pore space, and the permeability of the rock. Many reservoirs have fracture porosity only. These systems may have high deliverability and bulk volume but very low porosity and thus low hydrocarbon resource base. As performance data are obtained, it is usually possible to refine the initial estimates of these important reservoir attributes.

The bulk volume of a reservoir may be estimated from surface and subsurface geological and geophysical work. Information on area and structure may ke obtained from seismic studies and well drilling, whereas information on thickness is usually obtained from drilling and well logging. There are many cases where thickness measurement is not available because of poor response of logging devices in certain types of formations such as fractured shales, lime-dolomite sections, and fractured brittle rocks.

The fluid content of the reservoir is initially estimated from logging results and by direct determination on core samples, when these are available.

Successful coring programs must be able to cut and recover rock samples containing fluids representative of the formation. All phases represent problems to this day. Coring and logging may be required later in the life of a reservoir. A successful increase in oil recovery demands knowledge of the quantity of oil in place.

\section{DEVELOPMENT}

To plan the successive production phases of a reservoir (primary, secondary, and enhanced oil recovery), it is important to know details of the rock-fluid system. Sealing or leaky faults must be located and identified. Fractures (nature or type and location), permeability anisotropy, layering in the vertical sense, and other features must be determined. These features will frequently determine well patterns and spacing or number of wells. If there are trending fractures, fluid injection should be conducted normal to the fractures. 
Increased oil recovery, or application of new fluid-displacement processes developed subsequent to the advent of waterflooding, appear to offer the greatest potential to increasing oil recovery from existing oil fields. Recent studies (Lewin and Associates, Inc., 1976; National Petroleum Council, 1976) have inspected the potential near-term impact on the nation's oil reserves.

\section{WELL STIMULATION}

Stimulation of gas and oil wells is fundamentally important to the recovery of hydrocarbons from low permeability formations. Hydraulic fracturing, one method that has been employed extensively, is shown schematically in Figure 4.1. In many cases, this method has been most effective in increasing the production rate from uneconomical to economical levels; however, in some cases there has been little sustained increase in productivity. Design of hydraulic fracturing treatments with a higher probability for success requires improved understanding of the mechanics of hydraulic fracturing.

Containment of the fracture in the pay zone is one important consideration that requires investigation. Migration of the crack through the bounding impermeable barriers can be expected to be influenced by variations of in situ stress and rock properties from layer to layer as well as by the relative thickness of the bounding layers. In the absence of strong crack-arrest mechanisms, such as increased in situ compressive stresses or elastic stiffness of the bounding layers, it appears that fractures would tend to develop more nearly as circular cracks than as long cracks with height given by the height of the pay zone. Research on arrest mechanisms in layered formations can be expected to require a better understanding of the variation of in situ stress from layer to layer, as well as the strength of the bonding at the interface and the elastic properties of the fluid-filled, porous rock layers.

Improved techniques for measurement of the in situ stress state at a given depth and location are of considerable importance in hydraulic fracturing because, except near the well bore, the fracture can be expected to follow a path that is essentially perpendicular to the minimum compressive stress, unless another principal stress component is of comparable magnitude. Because knowledge of fracture orientation is essential to the development of efficient well patterns and enhanced recovery strategies, considerable improvement in reservoir exploitation would result from the availability of reliable, efficient means for determining in situ stress state. Detailed knowledge of in situ stress variation with depth may also contribute to the selection of zones that are attractive for hydraulic fracturing because of their potential for confinement of the fracture to the pay zone.

Another important consideration in hydraulic fracturing is the conductivity of the fracture produced. Improved understanding of the parameters influencing proppant distribution would be particularly valuable. Also, experience indicates that in some cases the crack, although open initially, apparently closes before a significant fraction of the resource is recovered; embedment of proppants into crack faces under in situ conditions is a possible explanation. Damage to matrix permeability during the hydraulic fracturing process should also be examined. Finally, new techniques for generating and propping cracks should be explored. Improvements in pumping rates and sequences, as well as in fracturing fluids, could perhaps be made if the mechanics of hydraulic fracturing of fluid-filled porous rocks were better understood. 


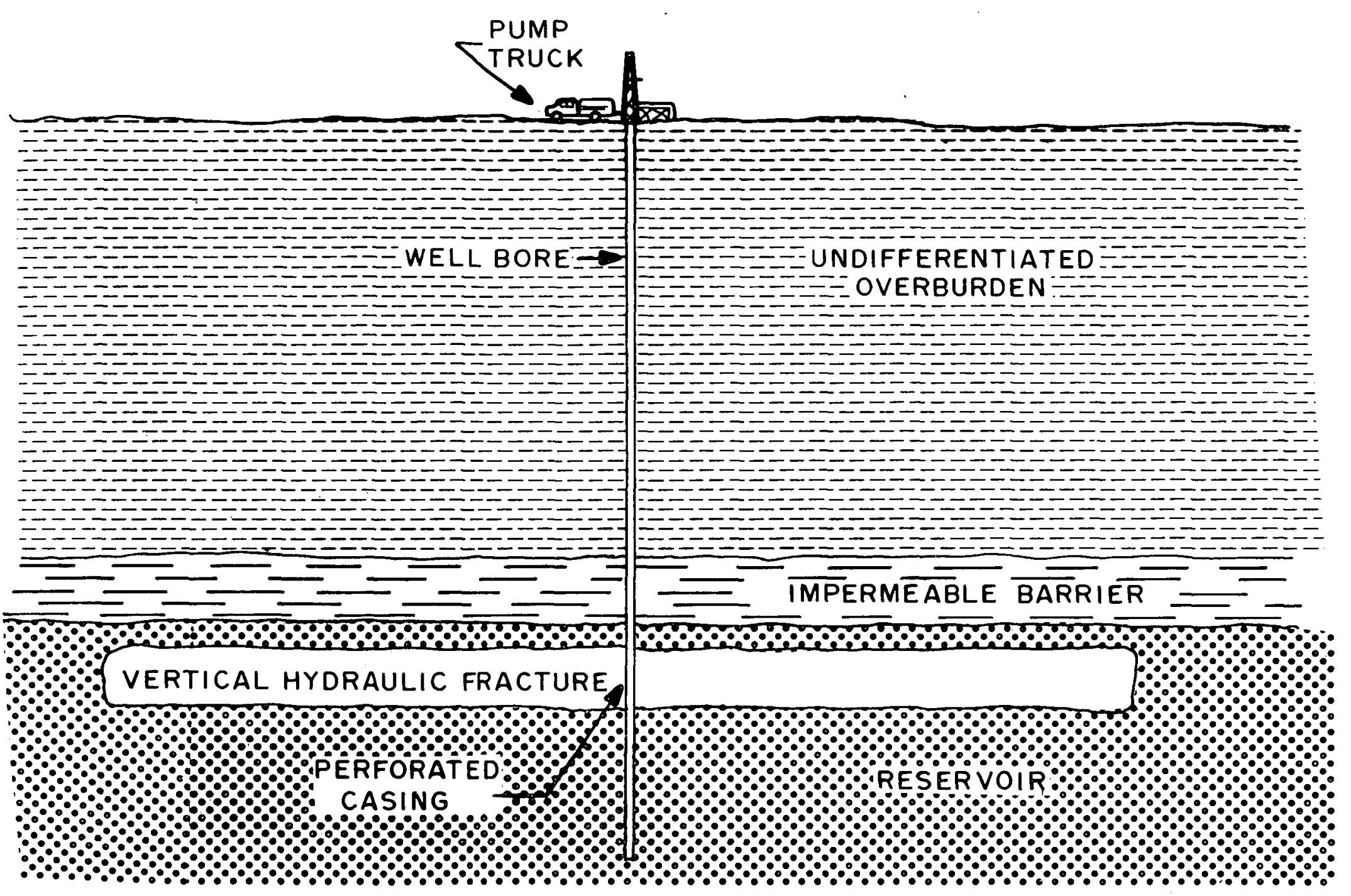

FIGURE 4.1 Schematic illustration of hydraulic fracturing to stimulate oil and gas wells. 
UNCONVENTIONAL HYDROCARBON SOURCES

With the depletion of the historic sources of gas and oil, the nation must necessarily direct more attention to analyzing the potential recovery of hydrocarbons from other sources. Chief among these potential sources are the recovery of gas and oil from tight formations, from shales and from saline water contained in the rock, from hydrocarbons absorbed on coal, and from hydrocarbons locked up in some other form in the permafrost regions of the world. The problems involved in the recovery of these mineral fuels are unique to the circumstances of their origin; however, each includes an urgent need to define and understand the distribution of the hydrocarbon material itself and how it is locked within the rock-fluid systems - whether the hydrocarbon is intimately mixed with host rock and hence would require extraction or whether it could be recovered in the future by drilling conventional wells, even if the recovery techniques are significantly different from those practical today.

Among the most important problems facing us is the recovery of gas and oil from low-permeability formations. Where these formations are sandstones and limestones the answers to problems can be found in an extension of the techniques used today. Where the hydrocarbons are more intimately intermixed with the organic shales, which are in themselves the probable source of the hydrocarbons, entirely new techniques may be required.

The eastern Devonian shales because of their widespread occurrence, their proximity to the large population centers, the detailed general knowledge that exists about their locale and thickness, and the minimal environmental impact, are likely to be among the first to be developed. There is a good general understanding of the hydrocarbons that may exist, but the detailed knowledge of how they are contained, the relative importance of the rock and fluid mechanics of the system as opposed to the physical-chemical characteristics, are known in only a rudimentary form. Without a significantly improved understanding of these elements, we can only begin to guess at the potential recoverable reserve, its cost, and when it can be used.

The western oil shales are much richer than the eastern shales and more localized, which should work in their favor. The activation energies required to release the hydrocarbon are larger; they are more remote from the centers of population, and the environmental problems present a conflicting melange of circumstances that makes the timing and recovery of this enormous resource uncertain. Here again much additional knowledge and detailed study of the rock-fluid system and how these properties vary geographically and with depth are needed.

Evidence is beginning to accumulate that large quantities of natural gas can be recovered by desorbing it from coal. This source of hydrocarbon may develop more as an incidental requirement to the safety of mining coal than as a valuable resource in itself. There is no doubt, however, that large quantities of gas are linked to the coal, and that it may be readily recovered using oil-field technology before the recovery of coal. 


\section{RECOMMENDATIONS}

The Subpanel concurred in the following list of suggested solutions to problems related to recovery of oil and gas. Some possible directions for research and development are given in parentheses below the applicable problem statements.

- Developing reliable, efficient means of determining in situ stress, fracture gradients, and direction of propagation of hydraulic features. (Notching borehole in two different directions and measuring in situ stress.)

- Developing inexpensive methods for coring and for analysis of cores. (Improved coring fluids-foaming agents perhaps. Improved pressure-coring techniques. Core-barrel servicing techniques.)

- Improving understanding of fracture mechanics of fluid-filled rocks. (More research on fluid flow in propagating fractures. Analytical or numerical work. Rate of crack advance-how drained versus undrained propagation proceeds.)

- Alleviating effects of high hydrostatic pressure on the bottom of the hole during drilling. (No obvious solution.)

- Improving drilling and directional drilling-better tools.

- Characterizing reservoir seals-early evaluation of potential hydrocarbon resources. (Tabulation of properties of seals of existing commercial oil and gas accumulations, including age of sea1, maximum and minimum thickness, present-day mechanical properties-including extensile and compressive strength, ductility-age of peak hydrocarbon maturation, and tectonic history of the sedimentary column. Look for minimum thickness of various seal lithologies in given deformational environments. This would probably require a full man-year effort.)

- Determining in situ values of $\mathrm{S}_{0}$, porosity, permeability, faults, flow barriers. Developing inexpensive instrumentation of high precision, e.g., cheap telemetering. Developing rugged, high-temperature and high-pressure logging devices.

- Determining porosity, permeability, and ductility variation of potential reservoir rocks with depth-reservoir storage and deliverability characterization. (Strength and ductility data exist for many end-member rock types; clean sands, lithographic limestones, selected shales. Very little information is available for quartz, poor sands, gypsum-anhydrite composites, or other compositionally heterogeneous sedimentary rocks. Very few laboratory measurements exist of permeability at elevated pressures. Field studies of porosity deterioration with depth are almost nonexistent. Basic research to fill in these gaps in knowledge is needed. Assuming that adequate characterization of a single rock type would require three man-months of effort in a laboratory set up to perform the required tests, several man-years of effort would be necessary to gather information on a representative suite of rocks. Because of the fundamental nature of this research, the results should find a much broader use than the evaluation of oil and gas reservoirs for which these measurements are here proposed.)

- Developing techniques for early characterization of systems of fracture porosity. (Improved recovery, early determination of commercial/noncommercial nature of the resource.)

- Improving the understanding of frequency and amplitude dependence of seismic velocities in fluid-filled rocks.

- Improving the understanding of effective pore-space compressibility of fluid-rock systems. 
- Developing methods for characterization and identification of "tight gas" resource base.

- Developing techniques for improved correlation of surface measurements with subsurface facts.

- Developing a national data base including field names, API (American Petroleum Institute) oil gravities, original oil in place (0OIP), and oil recoveries as of a particular date.

- Improving the understanding of the mechanical properties of ice and permafrost-safe Arctic drilling and production practices. (The mechanical behavior of permafrost and ice is still imperfectly known. Although work is being conducted on these materials, additional attention should be given to post-yield strength and deformational characteristics of ice to assess its impact on offshore structures both above and below sea level.)

\section{REFERENCES}

Ad Hoc Committee on Technology of Drilling for Energy Resources (1976), Energy Engineering Board, NRC Assembly of Engineering. Driliing for Energy Resources. National Academy of Sciences, Washington, D.C.

Lewin and Associates, Inc. (1976), for the Federal Energy Administration. The Potential and Economics of Enhanced Oil Recovery. Lewin and Associates, Inc., Washington, D.C.

National Petroleum Council (1976). Enhanced Oil Recovery: An Analysis of the Potential for Enhanced Oil Recovery From Known Fields in the United States 1976 to 2000. National Petroleum Council, Washington, D.C. 
5

\section{UNDERGROUND STORAGE - \\ FUEL OIL, GAS, WATER, OR COMPRESSED AIR}

Dougal R. McCreath

Subponel Chairman

\section{INTRODUCTION}

The function of the Subpanel on Underground Storage was to discuss and explore various modes of underground energy storage with a view to discerning rockmechanics problems that are currently limiting the utilization of innovative concepts.

Concepts of underground energy storage include a wide range of storage methods and of the forms of energy that can be stored. The three major methods of storage are as follows:

- Dry-mined storage, which is storage within conventiona11y mined caverns beneath the surface of the earth.

- Solution-mined storage, which is storage within caverns that have been formed by the process of solution mining, generally within salt. mass.

- Aquifer storage, which is storage within the pore volume of a rock

Energy can be stored underground using a wide variety of storage media, including the following: operation.

- Compressed air, used either directly or in conjunction with gas-turbine

- Water, for functions such as underground pumped storage, district heating, or direct thermal storage such as steam under pressure for peaking steam turbines.

- Hydrocarbons, ranging from cryogenic liquified natural gas to heated residual oil and including the full range of intermediate forms.

From these two lists, many permutations and combinations of underground energy storage are possible, with the storage-media properties ranging from low to high temperature and from low to high pressure and displaying a wide range of viscosities. In addition, the storage may be operated under either steady-state or cyclic conditions of temperature or pressure. The critical 
problems that arise with the storage facility will vary depending on the type of storage vesse 1 and the nature and properties of the stored medium. In preference to dealing with each individual combination of storage vessel and form of energy stored, the Subpane1 discussed the three broad classes of storage method or vessel-dry-mined storage, solution-mined storage, and aquifer (pore-volume) storage. Within each category the following questions were addressed:

- What are the rock-mechanics problems that are currently limiting the full utilization of the type of underground storage vessel under discussion?

- What programs of research and development could reasonably be undertaken to remove such limitations and permit fuller utilization of underground energy-storage options?

- Which research and development programs are of the highest priority, either because of specific applications that are desirable or because of the general applicability of a particular line of research?

Summaries of the Subpanel's discussions are recorded under the headings of dry-mined storage, solution-mined storage, and aquifer storage. Each section includes a brief overview of the storage method, a summary of the general discussion areas, and recommendations concerning research and development programs that the Subpanel considered to be significant to the further development of underground energy storage.

\section{DRY-MINED STORAGE}

Dry-mined storage consists of the storage of some form of energy within chambers that have been excavated within bedrock by mechanical means rather than by solution-mining methods, for example as shown in Figures 5.1 and 5.2. The chambers may have existed previously (e.g., an abandoned mine) or may have been specifically excavated for storage purposes. As we have mentioned, the storage medium may range from water at ambient pressure and temperature to gas (including compressed air) at high temperature and pressure, and it may include a wide intermediate range of fluids at a variety of imposed temperatures and pressures. At the low end of the temperature scale, concepts of liquified-natural-gas storage are currently being considered. For all the possible concepts and uses that have been considered, the fundamental objectives of each system are to provide positive containment of the stored medium and to ensure retrievability of the stored product-all within the framework of acceptable cost.

The basic principles of containment are fundamental to an understanding of the needed research areas that were discussed. These basic principles are summarized in the ensuing paragraphs.

For the most general case of an unlined chamber existing at some depth within a rock mass containing joints (fractures), containment of a fluid product depends on the existence of an adequate seal or leakage barrier within the joints. Ideally, such a seal may be obtained naturally by placing the facility within a geologic regime in which the following conditions exist:

water.

The rock mass surrounding the facility is fully saturated by ground-

- The pressure of the groundwater adjacent to the facility exceeds the storage pressure. 


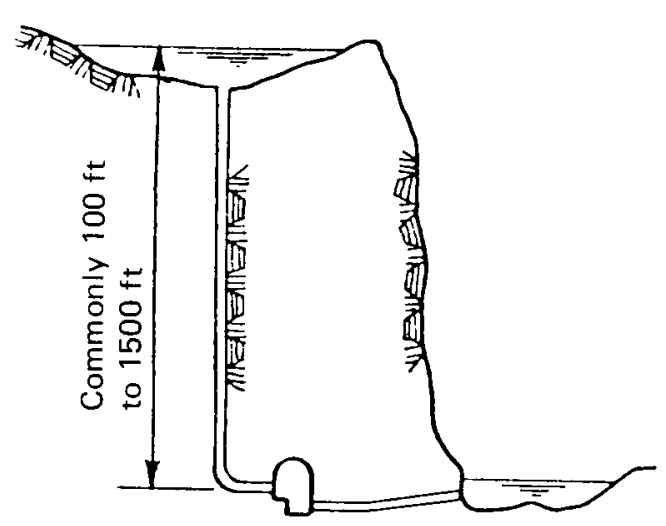

Conventional

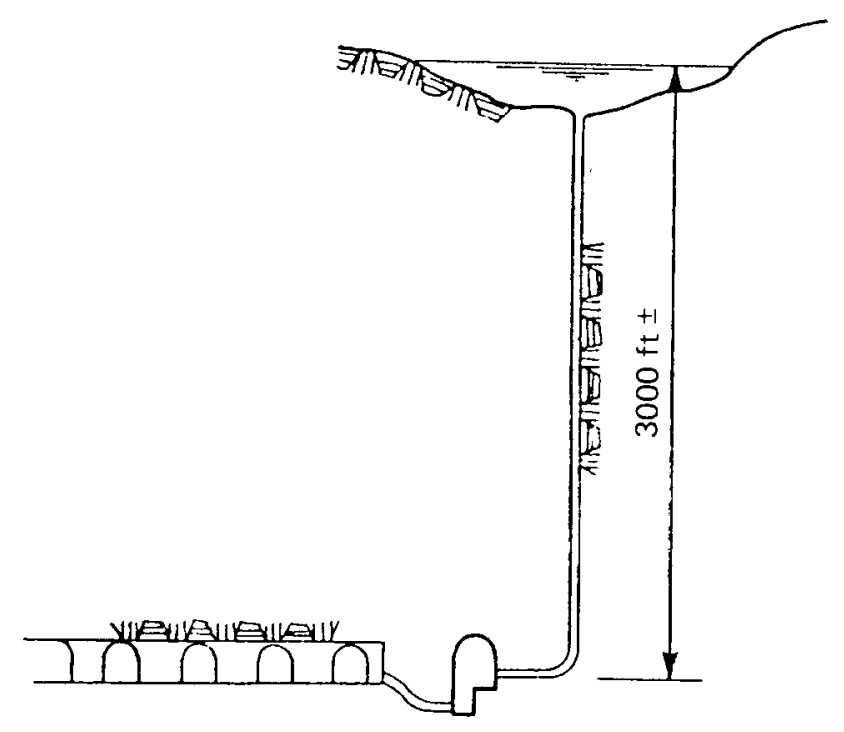

Underground

FIGURE 5.1 Underground pumped storage。
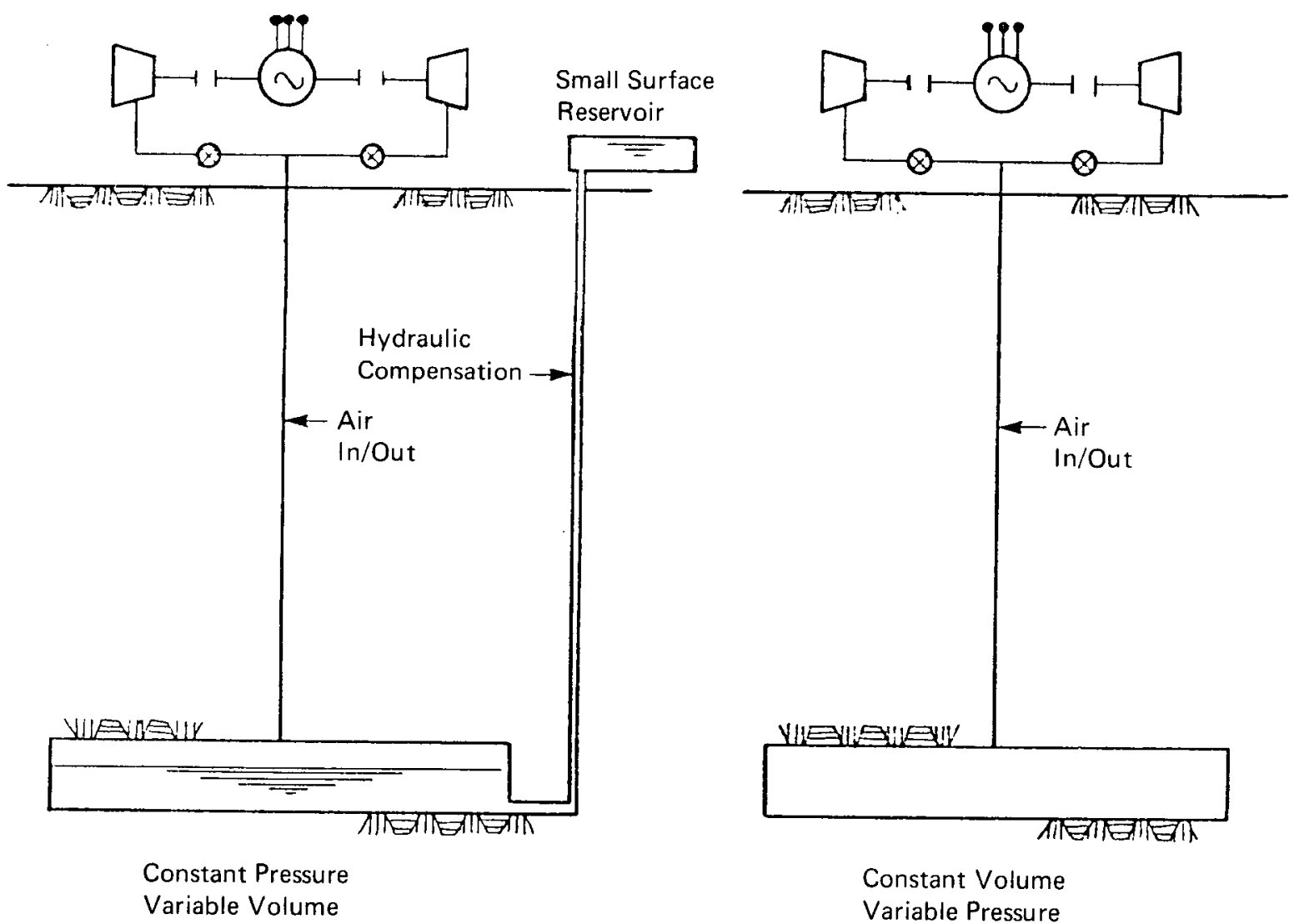

Constant Volume

Variable Pressure

FIGURE 5.2 Underground compressed air storage. 
- For stored materials of low density, the joint openings are sufficiently small and the hydraulic gradient of the groundwater flowing to the facility is sufficiently large to prevent leakage by bubbling.

If the above conditions cannot be met naturally, then the joints must be artificially sealed by some means to provide positive containment. Such means may include the installation of water-injection curtains or grouting using an appropriate material. It is important to recall that the stored materials may exist under a wide range of temperature, pressure, and viscosity and that the above requirements of containment must be maintained throughout this range. In addition the chambers must, of course, remain stable to ensure retrievabi1ity of the stored product. As always, these conditions must be fulfilled at an acceptable cost.

The broad question addressed by the group in connection with dry-mined storage was whether the state of the art of rock mechanics is adequate to enable confident prediction and monitoring of the coupled mechanical and hydrogeological effects that will occur in a jointed rock mass surrounding storage chambers. The question was reviewed within the context of widely varying temperatures and pressures of a stored medium as well as the widely varying nature of the surrounding rock mass with regard to rock type, fracture density, and other physical or chemical characteristics.

Rock-Mechanics Problems and Limitations

Throughout the discussions, it was persistently emphasized that our current knowledge of the mechanical and chemical responses of rock materials under extreme temperature conditions is significantly deficient. Certain storage concepts require knowledge of temperature-dependent response of rock materials under conditions from (about) $-260^{\circ} \mathrm{F}\left(160^{\circ} \mathrm{C}\right)$ for liquified natural gas to perhaps $800^{\circ} \mathrm{F}\left(430^{\circ} \mathrm{C}\right)$ for efficient adiabatic (second-generation) compressed-air storage. Knowledge of temperature-dependent response is necessary not only for a range of rock materials but also for rock-mass systems including the related joint or fracture systems. With reference to the general deficiencies in current knowledge concerning temperature response, some of the following additional factors were discussed:

- Rock-material and rock-mass response to fluctuating temperature and pressure conditions due to the mode of operation of the storage facility.

- The effect of extreme temperature conditions on the hydrogeological conditions in the surrounding rock mass and the consequent effect on containment efficiency.

- The effect of temperature conditions on cavern stability, particularly for those concepts requiring large-span cavities. Spans of greater than about $100 \mathrm{ft}$ for engineered caverns are currently outside the limits of precedent.

- For high-temperature storage concepts, the potential for chemical reactions between the parent rock and the stored materials, and the potential for accelerated weathering of the rock.

The potential need for providing artificial seepage barriers within the joint systems through injection of grout materials gives rise to concern over the performance of grout materials over a wide range of temperatures. In particular, the development of grouts that will perform adequately both under cryogenic conditions and under high-temperature conditions is important. 
In addition to the general concern related to temperature response of rock materials and rock masses, the prediction of hydrogeological behavior of the rock mass was discussed. It was generally considered that the development of adequate predictive tools that will enable the engineer to assess the hydrogeology of jointed rock masses of relatively low permeability was particularly necessary. For such predictive tools to be confidently utilized, they will require a program of field trials in which the predicted results may be calibrated against observed behavior. Related to the general discussion on hydrogeology and containment systems, certain additional matters were considered:

- The ability to predict, assess, and monitor hydrogeological response must include knowledge concerning the effects of induced high or low temperatures, variable pressures, and the effect of low-viscosity low-density materials used as the storage medium.

- Development is necessary of a better understanding of the available means of providing artificial containment through utilization of water-injection curtains and of injected grout materials. The range over which such containment tools are applicable is not well defined, i.e., in terms of joint spacing, the opening of individual joints, mass permeability, or conductivity.

- For certain storage concepts, maintenance of the purity of the stored product may demand some form of surface treatment of the rock chamber. Work is required to determine which methods of surface treatment may be most appropriate, as the cost of certain conventional methods of cavity lining (such as steel membrane linings) may be a significant economic factor for concepts such as the storage of steam as pressurized hot water for boiler feed-water storage.

In discussing the capacity of predictive tools, the Subpanel considered that this will inevitably depend on the ability to obtain confident input data through field exploration. The development of improved down-the-hole exploratory tools was considered to be a priority. The ability to measure engineering rock-mass properties at depth, specifically the hydrogeological characteristics and the in situ stresses, will be particularly important. The ability to extrapolate outside the immediate wall of the drill hole to determine the characteristics of the rock mass at a distance from the drill hole will be of economic significance because of the high cost of deep-hole exploratory drilling.

Following general consideration of research and development areas, the consensus of the Subpanel was as follows:

- Continuing research on limitations with regard to cavity spans and geometries should be supported, because the economic range of particular energystorage concepts may hinge on depth, size, and geometric limitations.

- Although it was considered that mode of behavior of underground storage chambers during seismic events is unlikely to be of a critical nature, it was agreed that because there are few test or analytical data currently available on seismic response of underground chambers, research in this area should be supported.

- Concerning our ability to monitor effectively containment performance of underground storage chambers, it was concluded that further work on the development of sensitive monitoring devices would be required, although this work had a slightly lower priority than developmental research in areas such as predictive capability for temperature response of rock masses.

- Demonstration pilot projects were considered to be a worthwhile form of development research, because such projects provide full-scale proving 
grounds for the suitability of predictive models and indicate problem areas of which we may not be aware.

The Subpanel's recommendations pertaining to research and development program areas for dry-mined underground storage are summarized in the following section.

\section{Research and Development Program Areas}

The Subpanel identified the following prime research and development program areas:

Temperature Response

- Study of mechanical and chemical response of rock materials and rock masses at elevated temperature, at cryogenic temperature, and at cycling temperatures. The acquisition of baseline data in this area would be expected to take 5-10 years.

Containment Systems

- The development of grouting materials appropriate to a wide range of temperature conditions and types of stored material.

- The development and field calibration of adequate predictive tools to assess the hydrogeology of jointed rock masses surrounding storage chambers, including effects of temperature and pressure variation.

- Development of better analytical understanding and predictive capabi1ity for the potential role of water-injection curtains in assisting the containment function of the rock mass.

Site Characterization

- Development of improved down-the-hole tools for better evaluation of in situ rock-mass properties, particularly hydrogeological characteristics, in situ stresses at depth, and characteristics of the rock mass at distance from the borehole walls.

\section{Demonstration Pilot Projects}

- Field-scale proving trials related to underground energy storage.

The following areas of research and development of less priority than those above were identified:

\section{Monitoring}

- Development of monitoring tools reliably to assess the containment efficiency of underground energy storage facilities.

Cavity-Wall Treatment

- Development and assessment of methods for the treatment of chamber walls in those cases in which great purity of the stored product is required. 
Depth, Size, and Geometry Limitations

- Continuing research is required to determine the practical implications of increasing chamber sizes and depths and of complicated geometric variations.

Seismic Response

- Development of test and analytical data concerning the integrity of underground storage facilities under earthquake conditions.

\section{SOLUTION-MINED STORAGE}

Solution-mined chambers within salt (solution jugs) have been used for storage of materials for many years both in North America and elsewhere. Commonly the stored material consists of liquified petroleum gases, although crude oil has also been stored in solution jugs. There is a project at present under way in Germany to utilize a solution-mined chamber for the storage of compressed air associated with a gas-turbine peaking plant. The general areas considered to be of significance in limiting the further utilization of solution-mined chambers for energy storage were discussed.

\section{Rock-Mechanics Problems and Limitations}

In reviewing current practice in solution-mined storage, and in looking to future potentials in the utilization of solution-mined chambers for energy storage, it was apparent that the area of temperature response was again of major significance. Little was known at present of the behavior of solution jugs under conditions of extremely low temperature or of extremely high temperature. For low-temperature applications, the tendency toward brittleness of the salt was not well defined. In addition, for high-temperature applications, the degree to which increased plasticity would adversely affect the storage function was felt to be an area where further knowledge was required. Other matters of a practical nature that may limit the use of solution jugs for energy storage include the following:

- The ability to measure accurately the geometry and volume of a subsurface solution chamber is at present inadequate, particularly for those applications in which the material being stored was of high value.

- Solution mining, by its nature, produces large volumes of saturated brine. The disposal of this brine creates problems, which may or may not be directly related to rock mechanics but must nevertheless be overcome. The method of brine disposal utilizing deep-well injection brings with it potential problems of aquifer pollution or earthquake generation. The Subpane1 considered, therefore, that further work on the question of brine disposal did fall within the general purview of rock-mechanics problems.

- There have been some recorded cases of structural collapse of solution jugs. The ability to predict confidently the long-term stability of such jugs will be a necessary tool in development of further underground-storage concepts in solution jugs.

Research and Development Program Areas

With regard to solution-mined storage, the following prime research and development areas were noted: 
Temperature Response of SaIt

- Continuing and expanded research on the temperature response of salt, both at the high- and low-temperature ends of the scale will assist in expanding the utilization of solution jugs for underground storage.

Fieid Measurement

- Field measurement of both geometry and volume of solution chambers to an acceptable level of accuracy for storage of valuable materials may require additiona 1 research.

Brine Disposal

- Environmentally-acceptable and cost-acceptable methods of brine disposal may require additional work, particularly in those areas where there is legitimate concern regarding potential earthquake generation caused by brine disposal.

\section{Solution-Mined Chamber Stability}

- Associated with continuing temperature-dependent research on salt properties, the ability to predict the long-term stability of solution-mined chambers under conditions of high or low temperature and fluctuating or steady-state temperature and pressure is necessary.

\section{AQUIFER STORAGE}

Rock types such as sandstone and limestone provide possibilities for the storage of fluids within the pore space of the rock mass. Existing technology derived from oil and gas production from such rocks has been used with little modification to replace and retrieve a range of fluids in large quantities for purposes of energy storage. The natural-gas industry has utilized both depleted oil and gas fields and water aquifers for the storage of billions of cubic feet of gas, which can be withdrawn during periods of peak consumption. Thus it was considered that the general technology of implacing and retrieving stored gases from within pore space of rock masses was well proven. Such technology was generally geared around the storage of materials at essentially ambient temperature conditions. Although several instances of leakage have occurred from such storage fields because of gas migration along undetected fractures, the technology is well established and dependable and is not really conducive to further major research or development efforts. The Subpanel discussed the possibilities of other forms of energy storage within aquifers, possibilities such as compressed-air and cryogenic storage, to determine whether rock-mechanics problems created limitations to the present development of such concepts. These limitations are discussed in the next section.

\section{Rock-Mechanics Problems and Limitations}

Current proposals for the storage of compressed air in aquifers raise the question of the storage of hot compressed air to maintain maximum energy efficiency when using the compressed air in association with gas-turbine power. generation. With current compressor technology, desirable storage temperatures for such schemes might approach $600^{\circ} \mathrm{F}\left(315^{\circ} \mathrm{C}\right)$, with pressures in the order of 
40-60 atmospheres. With second-generation equipment, desirable storage temperatures may increase to $800^{\circ} \mathrm{F}\left(430^{\circ} \mathrm{C}\right)$ or beyond. With regard to the pressures involved, it was believed that existing gas-storage experience is applicable to air storage in aquifers as long as the injection pressures are not more than 10 or 15 percent greater than pre-existing aquifer groundwater pressures. However, we lack experience in evaluating the long-term effects of high fluid temperatures on the pore structure of the aquifer and on the impermeability of the overlying cap rock. In general, fluid movement within a typical aquifer at depth may be of the order of a few feet per day, and, as typical shale cap rocks have low heat conductivity, heat migration should not be a limiting problem. Nevertheless, the direct effect of the heat on the structure of the aquifer rock and on the disintegration of the overlying cap rock is an area that is at present not well understood. Similar comments could be made concerning the lower temperature scale, although it is recognized that cryogenic storage within saturated aquifers is unlikely to be a practical storage concept.

Another source of concern regarding the present state of our knowledge in aquifer energy storage is the relation between injection pressures and the potential for earthquake generation along existing faults. Further research is warranted to study modes of earthquake generation related to injection of hot liquids and gases in aquifers traversed by existing faults. Also relevant and justified under research and development programs to promote energy-storage programs in aquifers would be programs to improve exploration and in situ testing techniques for the evaluation of cap-rock efficiency. Neither of these areas of potential research act as prime limitations to further energystorage concepts in aquifers.

\section{Research and Development Program Areas}

The three prime research and development program areas with regard to aquifer storage are as follows:

\section{Coupled Temperature and Pressure Effects}

- Laboratory and field study of both the short-term and long-term effects of the injection of hot and cold pressurized fluids on the properties and behavior of porous rocks. Both steady-state and cyclic applications should be investigated.

Accelerated Cop-Rock Degradation

- Laboratory and field study of accelerated weathering possibilities of aquifer cap rocks subjected to cyclic heating and cyclic wetting and drying.

\section{Irpact on Groundwater}

- Research on the potential for disturbance of existing groundwater regimes because of the storage of fluids at high pressure and temperatures.

Secondary development needs include the following: 
Earthquake Generation

- Study of the potential for earthquake generation along pre-existing faults caused by fluid injections.

Improved Recovery Technology

- Review of the state of the art of improved recovery techniques for the storage of relatively viscous fluid products. This technology exists mainly within the field of oil production. 


\title{
UNDER-OCEAN TUNANELING FOR PETROLEUM RECOVERY
}

\author{
H. Donald Outmans \\ Subpanel Chairman
}

\section{INTRODUCTION}

The Subpanel on rock mechanics problems in ocean tunneling for development and production of oil and gas recovery considers that this subject takes a unique position relative to the other groups of this Panel. Although both ocean tunneling and oil-field development and production are, each one separately, currently applied techniques, no oil field exists at present that has been developed from underground chambers reached by an access tunnel from shore. It should be recognized that rock-mechanics problems associated with this concept of oil-field development are only one facet of what this group sees as a whole host of technological problems and, at present, unknown environmental constraints.

To appreciate the nature of the problems that are to be solved if underocean tunneling for petroleum recovery is to be realized, the reader should have a clear understanding of the background of this new, untried, hybrid technology. Because of its cost, novelty, and complexity, it is likely to be limited to areas where no other practical solution of oil-field development exists: this means beyond the shallow nearshore Arctic.

The environment offshore in the Arctic is characterized by moving, shifting sea ice throughout most of the year, except for a brief ice-free period during the summer, which allows oil-field resupply barges to reach Prudhoe Bay. This sea ice can reach a thickness of $2 \mathrm{~m}$ late in the year and during most of the winter is driven aground in massive ridges and piles, from the shoreline out to a water depth of approximately $20 \mathrm{~m}$. This grounded ice is subject to slight movements during winter and normally breaks up with severe movements in the summer. Beyond the 20-m water depth, the moving Arctic pack, containing multiyear ice with ridges as thick as $40 \mathrm{~m}$ or more, shears along the coastline. The seafloor is commonly scoured to depths of $2 \mathrm{~m}$, and deeper scours have been reported.

Offshore exploration in such an environment has been carried out already in Canada, using artificial gravel or silt islands constructed in water depths 
up to $8.5 \mathrm{~m}$. Such islands must be designed to withstand lateral ice forces produced by the moving ice sheet during major storms and during summer breakups. The dynamic motion of sea ice near such a grounded obstacle together with the details of sea-ice fracture mechanics near the island boundary represent the major factors involved in the practical design of such artificial islands in the Arctic. From an engineering standpoint, these islands represent a simple extension of land-based technology and will undoubtedly be used near the shoreline in shallow water. However, in deeper water, the costs of island construction rise rapidly, and other alternatives for petroleum development facilities should be examined, both on technical and economic grounds. Steel and concrete structures represent one such alternative and merit serious consideration in any balanced program to examine petroleum extraction in the Arctic offshore. Massive structures would be required to support production facilities in the moving pack ice, and pipelines may require deep burial for protection against bottom-scouring ice features. The open-water season available for installation of such facilities may last only a few weeks each summer. Here again, lateral sea-ice motion and sea-ice failure mechanics against the structure dominate the design of the offshore structure. It is this area on which consideration of tunneling as an alternative to conventional surface development should focus.

It should also be emphasized that the petroleum exploration phase, in which major oil and gas deposits are located, will definitely involve drilling from artificial islands, structures, or floating platforms, all of which will be subject to at least some degree of ice interaction, depending on the projected season of exploration. Substantial petroleum reserves must first be found before the financial and other resources required for a long-distance tunneling project can be committed on a sound economic basis. Exploratory drilling operations must be conducted from the surface.

Assuming that an oil-bearing structure of sufficient magnitude has been defined in this manner, the concept of tunneling beneath the seafloor to a location above the petroleum reservoir and the drilling of the development wells from a chamber in this tunnel becomes reasonable. Such an approach completely avoids the ice hazards and has other potential advantages. Certain problem areas, such as the presence of offshore subsea permafrost, would be encountered, however, and it is the purpose of this report to discuss both the advantages and disadvantages of this possible approach and to recommend a plan to examine some of them in greater detail.

The existence of offshore permafrost as a potential problem in the development of Arctic offshore petroleum has been discussed from a technical standpoint in the National Academy of Sciences report, Problems and Priorities in Offshore Permafrost Research (1976). I Research conducted since that report was written has focused on the Prudhoe Bay region, because it is most likely to undergo early exploration. This condition will further limit the area of potential applicability of the tumneling approach on the Alaskan Arctic shelf.

\footnotetext{
${ }^{1}$ Ad HoC Study Group on Offshore Permafrost, Committee on Permafrost, NRC Polar Research Board, 1976. Problems and Priorities in Offshore Permafrost Research. National Academy of Sciences, Washington, D.C.
} 
It should be noted that only the upper boundary of the ice-bonded offshore permafrost has been explored, along a line extending $16 \mathrm{~km}$ seaward from Prudhoe Bay. Using seismic refraction and reflection, together with limited drilling and sampling, it has been tentatively established that the upper boundary drops quickly to about $40-\mathrm{m}$ depth at about $4 \mathrm{~km}$ from the shore and then decreases irregularly thereafter (Figure 6.1). It appears at present that the thawing of the upper boundary of the subsea permafrost is controlled primarily by convective transport of brine in the coarse, sandy gravels of the seafloor, rather than by conduction or diffusion. However, fine-grained sediments in specific locations could modify this considerably, and a nonuniform upper boundary of the permafrost should be expected. Geothermal heat flux is presumed to be melting the permafrost from below, at a rate of approximately $1 \mathrm{~cm} / \mathrm{yr}$, but no direct evidence of the lower-boundary profile beneath the sea has yet been obtained. To predict the type of permafrost conditions and properties that would be encountered by a specific under-ocean tunneling project, offshore permafrost should be mapped and diagnosed along the proposed route. Drilling, coring, seismic, and other remote-sensing methods should be used. As the tunnel construction proceeds, electromagnetic and acoustic sensing of the region scheduled for excavation may detect icerich areas, unfrozen brine pockets, and boundaries between bonded and unbonded material, which would assist in the choice of proper tunneling methods. In the construction of chambers for oil development, such remote sensing information would be of considerable value.

\section{ADVANTAGES OF UNDER-OCEAN TUNNELING}

At this point it is perhaps well to point out the many advantages inherent in this novel oil-field development method. We list the following advantages of under-ocean tunneling:

- Requires combination of two existing technologies - tunneling and oilwell drilling - and does not necessitate the development of novel technology.

- Allows use of onshore technology-dry well heads, conventional drilling rigs, hands-on maintenance, for example.

- Good working environment compared with harsh conditions on conventional Arctic rigs.

- Eliminates shutdown because of harsh weather.

- Simpler logistics than offshore drilling.

- Good underground living quarters for workers in Arctic.

- Pollution containment-no spillage in water or under ice.

- Less danger of sabotage.

- Eliminates problems of ice scouring.

- Provides dry production facility and pipeline corridor.

- Avoids major problems encountered with sea ice.

- Allows simultaneous use of several inexpensive land-drilling rigs

( $\$ 5$ million) compared with expensive offshore rigs ( $\$ 50$ million- $\$ 100$ million).

- Reduces number of deviated wells (i.e., allows more drilling sites).

- May be the only practical system for producing certain potential Arctic fields (e.g., deep water with multiyear ice).

- Material excavated from tunnel can be used for building roads, buildings, pads, islands, and causeways. 


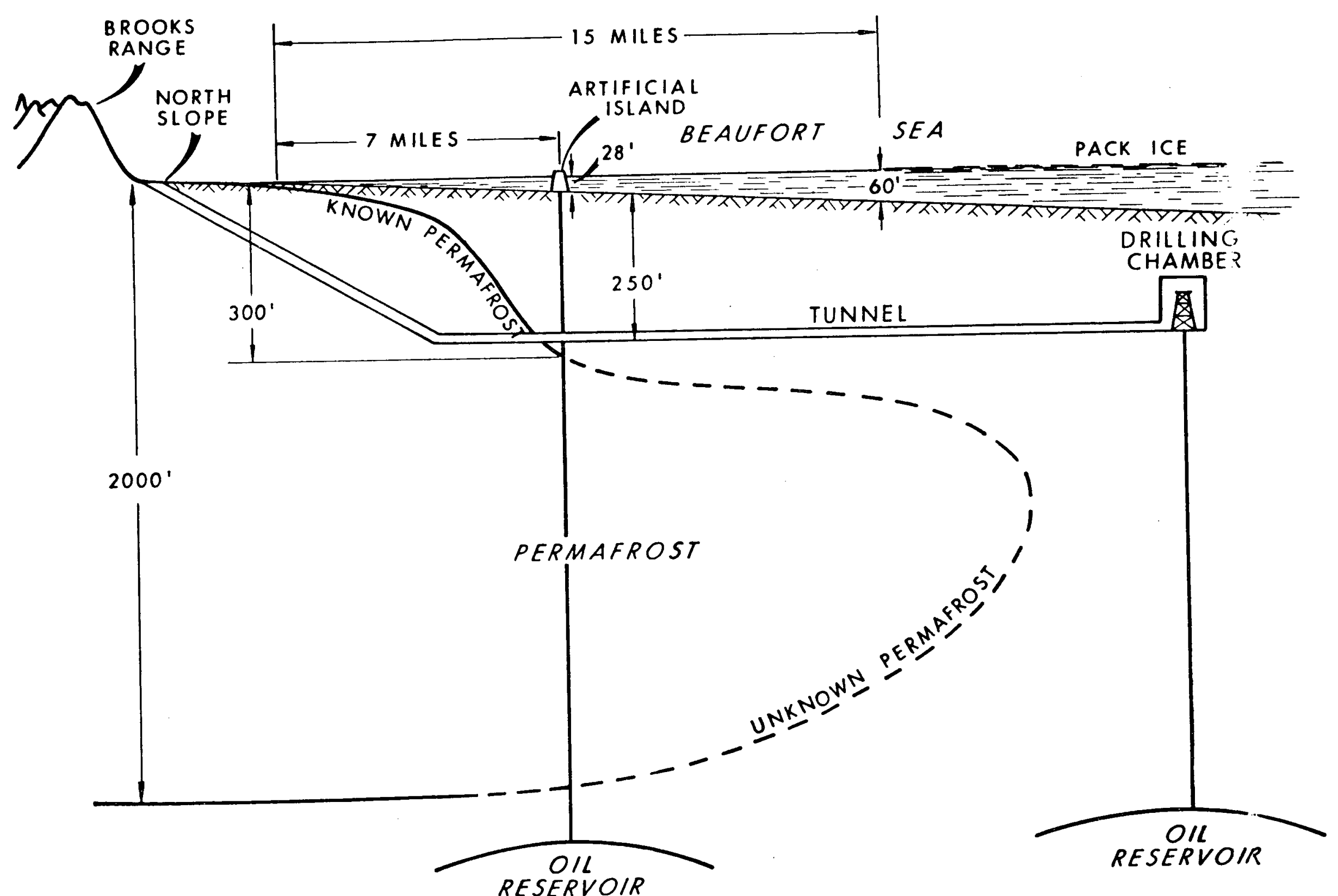

FIGURE 6.1 Development of oil reservoirs off the north Alaska coast. 


\section{EXISTING TECHNOLOGY FAVORS SHALLOW DEPTH OF TUNNEL}

The offshore oil fields of North America occur in a variety of geological settings, particularly with regard to water depth at the location of the field. In all instances, the sediments overlying the fields vary from unconsolidated to soft rock-usually sandstone, limestone, and shale. In the Arctic, there is a further consideration arising from the presence of permafrost.

In unconsolidated sediments, such as those occurring off the North Slope, it is likely that tunneling will only be practical at comparatively shallow depths because of the problems of dealing with the presence of water at full hydrostatic pressure with an infinite source. To deal with this problem, it will be necessary to use either grouting or the slurry mole concept at the probable depth of construction. Freezing is eliminated because of its inherently slow rate of progress, and the use of compressed air is unlikely because of problems of toxic effects at the pressures necessary to balance the hydrostatic pressure at the comparatively great depth of construction.

The presence of bonded permafrost in unconsolidated sediment will be helpful, but its continuity cannot be anticipated because of the presence of relic thaw bulbs or unfrozen brine lenses. It will therefore be necessary to have available the same procedures as would be used in unbonded soil. This fact essentially determines the technique, since changing from one to another is not practical.

Rock, whether in permafrost or not, offers the opportunity to use tunnel-boring machines of advanced design with high penetration rates. However, as depth increases, so do the risks of disastrous water influx through faults or other previous fractures. There is also the possibility of encountering zones of fragmented rock also associated with faults and shears.

For all conditions, shallow construction is desirable from the point of view of minimizing water head; but in rock, it may prove better to have the tunnel located at a depth such that it is sure to be in sound, unweathered rock.

The rock-mechanics problems associated with design and construction of either soft-ground or rock tunnels not in permafrost will, in general, be the same as for all soil tunnels. It will be necessary, however, to conduct detailed studies of the behavior of permafrost in relation to Arctic tunnels and, in all cases, to gather complete information conceming possibly adverse structural conditions.

The depth at which such tunnels will be constructed in soft ground will strain the limits of current construction technology. It will be necessary to examine each separate element of design and construction to ensure safe, rapid, and economic completion of this project. Because of the many problems that have to be solved to verify the practicality of the concept, the Subpanel recommends, as a first approach, a feasibility study. 


\section{FEASIBILITY STUDY}

A feasibility study on drilling oil and gas wells from tunnels should include the following:

- Scenarios for underground oil-field developments

- Advantages and disadvantages of drilling from tunnels

- Rough cost and time estimates (tunneling)

Shallow $(<250 \mathrm{ft} ; 75 \mathrm{~m})$

In permafrost $(0-2000 \mathrm{ft} ; 600 \mathrm{~m})$

Below permafrost (>2000 ft; $600 \mathrm{~m})$

- Rough cost and time estimates (oil and gas drilling and production)

- Safety and environmental factors

- Regulatory factors

- Technical limitations (tunneling)

Groundwater

Creep

Advance rate

Lining design and installation

Material removal

Ventilation

Grouting

Thermal stresses

Permafrost freeze-thaw cycle

Buoyancy of tunnel

Subsidence

Chamber excavation

Chamber stability

- Technical limitations (oil and gas drilling and production)

Well control

Logistics

Drillstring tripping

Adaptation of drilling production technology to tunnel environment

- Parameters for pilot project

- Recommendations

The tunneling portions of these studies should be conducted jointly by persons from the tunneling and petroleum industries.

The scenarios should include tunneling from shore or from islands to hypothetical fields at various distances and water depths. Conceptual designs should be completed for these different cases and the most serious limitations addressed. Offshore structure mapped by the USGS should be assumed to contain oil and used in these case studies. This case structure can be moved to different distances from shore and corresponding water depths. Several field recovery levels of, say, 1 billion to 10 billion barrels should be addressed.

Among the subjects to be addressed in the feasibility study, we point out the following problem areas that, in the opinion of the Subpanel, need special attention. 


\section{PROBLEM AREAS}

\section{Rock-Mechanics and Constructability Factors}

Before an assessment of construction problems and costs can be made, the following rock-mechanics factors must be ascertained and tabulated:

A geological description must be given the various formations that the construction experts could expect to encounter. The material must be identified as rock or soil, igneous, sedimentary, or metamorphic rock. What is the strength, hardness, permeability, or jointing? Are faulting or other discontinuities present? Is permafrost present?

This geological information is needed to predict the following factors:

- Method of excavation

- Probable rate of excavation

- Structural supports

- Lining design

- Groundwater infiltration

The depth of tunnel invert below sea level and the depth of ground cover-tunnel roof to seafloor-are needed to predict:

- Groundwater infíltration

- Lining design

The following nongeological factors will affect cost and construction time:

- Length of tunne1

- General accessibility

- Method of access

Shaft onshore

Adit onshore

Shaft from offshore site

Adit from offshore site

- Disposal method and location

- Weather conditions at site

- Logistics

- Life-support facilities

- Source of energy

- Source of freshwater

- Communications

- Transportation facilities

- Recreational facilities for workmen

\section{Cutting and Boring in Frozen Ground}

Mechanical cutting and breaking techniques that utilize drag bits or indentation tools are directly applicable in frozen ground. In broad terms, drag bits are well suited for cutting ice and frozen fine-grained soils, whereas indentation tools (roller cutters, percussion tools) may be required in coarse or bouldery frozen gravels. 
The design of cutting and boring machines is not normally determined by specific material properties, and existing machines can be adapted for work in frozen earth materials. Material properties have to be taken into account when selecting machines and operating parameters for particular jobs.

Basic knowledge of the mechanical properties of frozen materials provides a general impression of deformation and fracture characteristics and how they vary with material type, ice content, temperature, strain rate, and stress state. However, very little work has been done outside the Soviet Union to determine the cutting characteristics of frozen soils.

It would be desirable to carry out cutting experiments on frozen materials with both parallel-motion tools (drag bits) and normal indentation tools (mainly disks and studded rollers). The relevant research methods have been developed and applied to a variety of rocks and minerals. It would not be necessary to cover all the experimental variables when working on frozen materials. The main object would be to discover how the properties of the frozen materials affect the dynamics and energetics of the cutting process.

\section{Sensing of Ground Conditions Ahead of Face and Around Bore}

A remote-sensing technique for exploring ground conditions (soil type, ice content, freeze state) would be either necessary or desirable. This technique might involve a combination of elastic-wave and electromagnetic methods (active and passive).

\section{Exploratory Drilling for Route Survey}

Core drilling along a proposed tunnel is obviously required for design and construction planning and to provide ground truth for remote sensing. There are problems with extracting and handling core to maintain it in an undisturbed state, free from contamination, water-content changes, and temperature disturbances. Core holes also have to be logged for temperature.

\section{Effects of Heat Flow and Thawing on Permafrost}

Heat flow (positive or negative) from a tunnel can heat or melt permafrost, cool or freeze soils, or maintain a steady-state condition. Heating accelerates creep rates; thawing produces subsidence; cooling slows creep; freezing can produce expansion, frost heave, ice segregation, and frost damage to rocks and concrete. Thawing of massive ice bodies of ice-rich frozen soils could create a buoyant condition for a lined tunnel, or it could lead to differential settlements along the line of the tunnel.

Heat 'Control During Tunneling

It seems likely that all heat created by mechanical, thermal, and electrical processes will have to be removed from the tunnel. Most of the energy taken underground will finish up as heat-only the energy used for such purposes as potential energy processes (lifting, irreversible strains, surface-free energy) and kinetic energy output (fluid or muck streams) is exempt from the heat-removal tally. 
Heat Control During Operation of the Facility

Even if the tunnel and chambers are fully lined, there may well be a requirement for operating with skin temperatures of $-10^{\circ} \mathrm{C}$ or lower that could involve special ventilation or artificial refrigeration schemes. Requirements for hot oil lines and cold tunnel walls might have to be reconciled.

Muck Removal

There are potential problems with refreezing of permafrost cuttings and rubble in cars or piles, related to vapor diffusion, temperature gradients, and material type.

Cutting, Breaking, Excavating

Properties of frozen soils need to be taken into account in designing boring heads.

Frozen fine-grained soils with moderate to high ice content are ductile at low strain rates. Fullface boring heads tend to have low tool speeds near the center of the head.

Coarse, cobbly gravels with ice bonding are difficult to cut.

Tunnel Advance Rate

Drilling of the access tunnel delays the onset of development drilling. The length of this delay is sharply dependent on the advance rate and more so as the field is farther from shore.

Cost

Typical costs of existing tunnels of the type suggested for the Alaskan North Slope offshore are in the range of $\$ 3$ million to $\$ 15 \mathrm{million} / \mathrm{km}$ for a $4-5-\mathrm{m}-$ diameter tunnel, depending on subsurface conditions. Significantly higher costs must be expected for such tunnels in the Arctic. Compared with this cost, the expenditures for excavating the drilling chambers and for tunne1boring equipment are minor.

\section{Well Control}

Well control has been an area of great concern in offshore drilling, and a great deal of effort has been expended in controlling oil wells under various situations. Many of the solutions and methods developed for the control of these conventionally drilled wells are directly applicable to those drilled from subsurface chambers. However, because of the nature of the tunnel environment, special precautions will have to be taken with the handling of larger volumes of gas. Methods for handling large volumes of gas need to be considered (such problems are compounded with sour gas flows), and means of disposing of gas need to be studied.

In deep tunnels, the pressure is greater at depth than at the surface; this has to be taken into account. Research is needed regarding handling ignited gas with the well out of control. Handling of fluid flows resulting from blowout needs to be studied. A means must be developed to re-establish 
control of the we11. Care must be taken that, in case of a blowout, excess fluid can be vented by pipeline to the outside to avoid pressure buildup in the chamber and possible breakthrough into the chamber roof.

Spudding In

Control of formation fluid when spudding in requires development of special techniques. There is a need for pul1-down on rig and rotary head to overcome formation fluid pressure.

Pulling of singles during tripping with the bit or a flex-pipe rig should be considered. Handling of drill cuttings and drilling mud requires attention, as does disposal of these materials.

\section{Safety}

Rapid evacuation of personnel in case of an emergency needs to be studied in depth. There is a need to provide an alternate escape system. Protection of personnel against falls (ground control) is needed. Mechanical safety of equipment must be provided, including well-control systems. Remote wel1 control needs to be studied to manipulate controls from outside the tunnel, above the ice. Existing hardware must be adapted and modified for applications in drilling from subterranean chambers. Familiarizing oil-field personnel with unfamiliar subterranean environment is important. Use of experienced oil-field personnel for the oil-well drilling, rather than miners, is desirable.

\section{Identification of Economic Parameters}

This is an important part of any study so that cost-effective decisions can be made.

\section{Production}

During the production phase (20-30 years) it may be desirable to insulate (refrigerate) the pipeline to maintain the permafrost if this is necessary for the integrity of the tunnel and the drilling chambers. The latter should be designed with the production phase in mind right from the beginning.

\section{EXPERIMENTAL TUNNEL FACILITY}

Assuming that the practicality of the concept is proven in the feasibility study, the Subpanel recommends, for the next phase, the construction of an experimental tunnel facility. The purpose of this facility would be to gather information about thermal and mechanical properties of soft sediment permafrost in situ. We visualize a facility perhaps $60 \mathrm{~m}$ long and $3.6 \mathrm{~m}$ in diameter (about the diameter of the ocean tunnel). We estimate the cost of this near-term project (less than 4 years' duration) to be $\$ 1$ million. This facility, of course, would be permanent and could be utilized for other permafrost-related studies.

\section{OCEAN-TUNNEL PILOT PROJECT}

Following successful completion of the test program in the experimental tunnel facility, the Subpanel envisages boring a full-size (3.6- to 4.8-m-diameter) 
tunnel $300 \mathrm{~m}$ long. Estimated cost would be $\$ 10$ million to $\$ 15$ million (1977). It would be advantageous if, when this pilot project is begun, some oil-bearing structures beyond the fast ice had been proven productive. This would make possible the continuation of the pilot tunnel or a full-access tunnel after testing in the pilot tunnel was satisfactorily completed. The Subpanel considers the ocean-tunnel pilot project to be a necessary and natural extension of the earlier experimental tunnel facility. The main and vital purpose of the project would be to develop and perfect the ability to bore the full-length tunnel. However, it should be pointed out that a 300-m-long pilot-project tunnel, as envisaged, would most probably be located entirely within the bonded permafrost and would not be a complete test of conditions further offshore in the unbonded permafrost.

\section{CONCLUSION}

Under-ocean tunneling for petroleum recovery appears to be a reasonable concept and perhaps the only practical method of recovering oil from reservoirs located beyond the shallow nearshore Arctic. The Subpanel is aware of the many developmental problems associated with this hybrid technology. These problems need to be solved, and we have suggested a series of steps that can be taken to solve them. We believe that rock mechanics can contribute to many aspects of this research and development program. In turn, the results obtained in the proposed experiments are likely to find applications in other areas where rock mechanics can improve our understanding and help to achieve national energy objectives. 
$\theta$

$\theta$ 
MEMBERSHIP 1976 - 1977 ,

U.S. NATIONAL COMMITTEE FOR ROCK MECHANICS

\section{OFFICERS}

George B. Wallace, Chairman

Principal Engineer

Bovay Engineers

Spokane, Washington

Thomas C. Atchison, Chairman-Elect

Department of Civil and Mineral Engineering

University of Minnesota

\section{MEMBERS AT-LARGE}

Norman A. Dixon, Staff Geologist

Office of the Chief of Engineers

U.S. Army Corps of Engineers

Washington, D.C.

Ronald E. Heuer

Department of Civil Engineering

University of Illinois

William A. Hustrulid

Terra Tek

Salt Lake City, Utah

(on leave from College of Mines and Mineral Industries, University of Utah)

Andrew H. Merritt

Don U. Deere and A.H. Merritt, Inc.

Gainesville, Florida

Howard J. Pincus

Department of Geological Sciences

University of Wisconsin, Milwaukee 
SOCIETY REPRESENTATIVES

Society of Mining Engineers (SME)

Jose F.T. Agapito

Consultant

Grand Junction, Colorado

Geological Society of America (GSA)

Bruce R. Clark

Department of Geology and Mineralogy

University of Michigan

Transportation Research Board (TRB)

George B. Clark, Senior Research Associate

Excavation Engineering and Earth Mechanics Institute

Colorado School of Mines

American Society of Mechanical Engineers (ASME)

Sidney J. Green, President

Terra Tek

Salt Lake City, Utah

American Society of Civil Engineers (ASCE)

Don E. Banks, Chief

Engineering Geology and Rock Mechanics Division

Waterways Experiment Station

U.S. Army Corps of Engineers

Vicksburg, Mississippi

Society of Petroleum Engineers (SPE)

William C. Maurer, President

Maurer Engineering, Inc. ,

Houston, Texas

American Society for Testing and Materials (ASTM)

Egons R. Podnieks

Research Supervisor, Surface Mining

Twin Cities Mining Research Center

U.S. Bureau of Mines

Twin Cities, Minnesota

Society of Exploration Geophysicists (SEG)

Gerald B. Rupert, Senior Research Investigator

Rock Mechanics and Explosives Research Center

University of Missouri, Rolla

American Geophysical Union (AGU)

Christopher H. Scholz, Senior Research Associate

Lamont-Doherty Geological Observatory

Palisades, New York

Association of Engineering Geologists ( $A E G$ )

David T. Snow

Department of Geology

Colorado School of Mines 


\section{LIAISON REPRESENTATIVES}

Building Research Advisory Board (BRAB)

John P. Gnaedinger, President

Soil Testing Services, Inc.

Northbrook, Illinois

Interagency Committee on Excavation Technology (ICET)

Eugene C. Robertson

U.S. Geological Survey

Reston, Virginia

Transportation Research Board (TRB)

John W. Guinnee

Engineer of Soils, Geology, and Foundations

Transportation Research Board

National Research Council

Washington, D.C. 